\title{
Dante en la cultura catalana a l'entorn del Casal de Barcelona (I38I-I4IO/I2)
}

\author{
Francesc J. Gómez \\ Universitat Autònoma de Barcelona \\ FrancescJosep.Gomez@uab.cat \\ http://orcid.org/OOOO-OOO3-O250-2277 \\ Received 20/o6/20I6; accepted o8/o9/20I6 \\ DOI IO.7203/MCLM.3.8433
}

\section{Dante in Catalan culture around the House of Barcelona ( $138 \mathrm{I}-\mathrm{I} / \mathrm{IO} / \mathrm{I2})$}

\begin{abstract}
This article analyzes in a historical context the earliest evidences of Dante's influence on Catalan culture during the reigns of Kings Peter IV, John I and Martin of Aragon, until the interregnum (I4IO-I2) and the change of dynasty resulting from the Compromise of Caspe (I/I2). French courts, Avignon papal curia and the close personal, political and dynastic ties between the kingdoms of Sicily and Aragon constitute the background on which this paper studies the many echoes of Dante-from the Commedia, from the commentaries on Dante and from the so-called silloge boccaccesca-to be found around the chancellery and the court of Aragon: specifically, in Bernat Metge's Llibre de Fortuna e Prudència (I38I) and Lo somni (c. I398); in Andreu Febrer's, Gilabert de Pròixida’s and Melcior de Gualbes' poetry; in one letter from Martin of Aragon (I4O8), and in Felip de Malla's early predication (I4II, I4I3).
\end{abstract}

\section{KeYwords}

Dante Alighieri; Dante in Catalan culture; Anselm Turmeda; Bernat Metge; Felip de Malla; Antipope Benedict XIII; King Martin of Aragon; Andreu Febrer; Gilabert de Pròixida; Melcior de Gualbes; Christine de Pizan and Dante; Dante in Sicily.

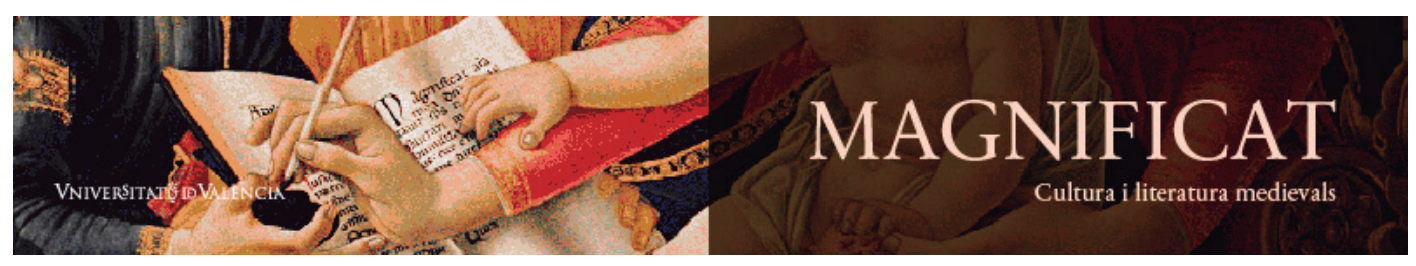

Magnificat Cultura i Literatura Medievals 3, 20I6, I6I-I98. http://ojs.uv.es/index.php/MCLM

ISSN $2386-8295$ 
RESUM

L'article analitza en un context històric les primeres mostres d'influència de Dante en la cultura catalana durant els regnats de Pere el Cerimoniós, Joan I i Martí l'Humà, fins a l'interregne (I4IO-I2) i el canvi de dinastia resultant del Compromís de Casp (I4I2). Les corts de França, la cúria papal d’Avinyó i, sobretot, els estrets lligams personals, polítics i dinàstics entre la Corona d'Aragó i el regne de Sicília constitueixen el rerefons sobre el qual s'estudien els nombrosos ressons de Dante -la Commedia, la crítica dantesca i el Dante líric de l'anomenada silloge boccaccesca- a l'entorn de la cancelleria i la cort d’Aragó: concretament, en el Llibre de Fortuna e Prudència (I38I) i en Lo somni (c. I398) de Bernat Metge; en l'obra lírica d'Andreu Febrer, Gilabert de Pròixida i Melcior de Gualbes; en la correspondència de Martí l’Humà (I408), i en la predicació de Felip de Malla (I4II, I4I3).

PARAULES CLAU

Dante Alighieri; Dante en la cultura catalana; Anselm Turmeda; Bernat Metge; Felip de Malla; Benet XIII d’Avinyó; Martí l'Humà; Andreu Febrer; Gilabert de Pròixida; Melcior de Gualbes; Christine de Pizan i Dante; Dante a Sicília.

Projecte FFI2OI4-53O5O-C5-4-P finançat pel Ministeri d'Economia i Competitivitat

Francesc J. Gómez. 20I6, 'Dante en la cultura catalana a l'entorn del Casal de Barcelona (I38II410/I2)', Magnificat Cultura i Literatura Medievals, 3: I6I-198 (ल्) Br

\section{TAULA DE CONTINGUTS}

I Per què tornar-hi - I63

2 Dante i els lectors del Roman de la Rose - I65

3 Dante, Petrarca i Boccaccio a Avinyó - I72

4 Trobadors, lírica francesa i Dante estilnovista - ${ }_{17} 6$

5 Una connexió siciliana ( 1367 -I/413) - I79

6 Entre Sicília i Barcelona - 185

${ }_{7}$ Obres citades - 188 


\section{ə*⿻丷木}

\section{Per què tornar-hi}

D escriure la fortuna de Dante en la cultura catalana ha esdevingut un exercici recurrent $\mathrm{i}$ profitós durant més d'una centúria, especialment pel que fa als primers testimoniatges medievals, d'una precocitat, una qualitat i una abundància extraordinàries en el context europeu. ${ }^{\mathrm{I}}$ L'esforç d'inventariar-ne els documents -ressons, mencions, citacions, imitacions, traduccions, notícies d'inventari, testimonis conservats- i d'integrar-los en una perspectiva històrica no solament beneficia la memòria d'un poeta universal i dels primers lectors que el van saber apreciar, sinó que sobretot ens ajuda a comprendre un element essencial en l'evolució del sistema literari i l'horitzó de referències de la cultura catalana i europea.

Més que no pas l'aparició de nous documents, és sobretot l'estudi aprofundit dels documents coneguts i del seu context sociocultural el que ens obliga a actualitzar periòdicament aquesta perspectiva, confirmant o qüestionant aportacions anteriors més o menys hipotètiques. Per exemple, Mario Casella (I966 [ı919]: 208-209) i Arturo Farinelli (I922: 6I n.) observaren raonablement que l'establiment a Catalunya de mercaders italians com Baldassarre degli Ubriachi ${ }^{2}$ podria haver-hi contribuït a la difusió de Dante des de final del segle xIV, atès que molts mercaders italians solien citar Dante en la seva correspondència: Simone di Bartolozzo, el pisà Agnolo di Ugolotto o Lotto degli Agli, el notari ser Lapo da Prato en moltes cartes adreçades al mercader pratès Francesco Datini (Livi rgıo: 23-24 i n. 4). Certament, l'argenter Joan de Pisa (Soler i Palet I92I: 154-57; Gómez 2OI6: I79-8I) proporciona a mitjan segle XV un exemple tangible de docència dantesca en la Barcelona de I458, i potser ja en la València de I424, on treballà al servei d'Alfons el Magnànim i on exercia docència un gramàtic venecià anomenat Guillem. ${ }^{3}$ Però la importància de mercaders, artesans i banquers italians en la difusió de Dante al segle XIV és encara una hipòtesi raonable que no podem contrastar ni mesurar (Boni ig67: 396 n. 40).

I. L'estat de la qüestió ha canviat considerablement des de les notícies i ressenyes pioneres de Sanvisenti (I9O2),

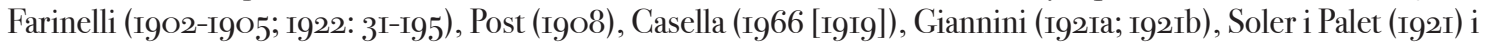
Friederich (I950: I5²I, 55-53); especialment precises són les síntesis de Boni (เ967), Arce (I965; I976) i Gómez (2OI4: $3 \mathrm{I}-5 \mathrm{O})$.

2. El mercader florentí Baldassarre degli Ubriachi exercia de banquer, d'agent polític de Milà i de tallador d'ivori. L'estiu del I399 viatjà per la Corona d'Aragó, Navarra, Aquitània, Anglaterra i Irlanda, com a joier i venedor de mapamundis elaborats a Perpinyà pel cartògraf convers Jaume Ribes (Jafuda Cresques, fill d’Abraham) i pel genovès Francesco Becca. El I3 de juliol de I399 escriu des de Saragossa a Simone d'Andrea, a Barcelona, dient que ha esdevingut molt familiar de Martí l'Humà, que hi conversa en privat al seu estudi i que el rei l'ha fet del seu consell: “Dappoi ch'io non ti scrissi, mi sono molto dimesticato con questo nobile signore Re, il quale m’à posto grande amore, e a ogni mio piacere mi vo a stare collui a solo a solo nel suo studio, e volentieri m’ode e pratica e ragiona mecho, e per la sua benignità gl'è piaciuto farmi di suo stallo e di suo consiglo", probablement com a informador polític (Livi I9II: 206). Però ni Livi ni Farinelli no poden confirmar que fos lector de Dante.

3. Encara que no constés formalment en el currículum escolar, la Commedia hauria pogut ocupar algun espai en la docència de mestres italians com Guillem, persuadit d'establir-se a València procedent de Nàpols, on tenia estudi i escoles d'arts, "quis era profert legir per hun any aquel libre o libres de poetes que volrien”, i al qual el 28 de setembre de I424 s'assignaren cent florins anuals per "legir publicament en la casa del consell de la dita Ciutat lo libre de Virgili eneydos e lo libre de boeci de consolacio" i “daltres actors poetichs e morals" (Vives i Liern I9O2: 7O-7I, esp. 7I per al doc. [I3 d'octubre de I424]; Farinelli I922: 64-65 i nn.; Sanchis Sivera I999 [1930]: 80 i n. I). El I461 el Consell de València assignà al poeta i orador Francesco Boccinis un salari de cinquanta-cinc lliures anuals per “legir libres de poesia e altres" (Vives i Liern I9O2: 74-75; Farinelli r922: 64-65 i nn.; Sanchis Sivera I999 [I930]: 80 n. 2, amb doc.). 
Igualment raonable però difícil de determinar és el coneixement que pogueren adquirir de Dante els estudiants catalans - notaris, juristes, doctors en dret canònic o teòlegs - formats a Bolonya 0 en altres universitats italianes al segle XIV, dels quals Marco Boni (I967: 394-95) dreça una llista significativa. És versemblant que algun d'aquests estudiants s'encomanés del culte de Dante i se’n procurés un manuscrit, tot i la manca de documents que ho acreditin.

El cas del franciscà mallorquí Anselm Turmeda mereix una atenció particular. En el relat autobiogràfic de la Tuhfa, Turmeda assegura que estudià a Bolonya entre I375 i I385 -des d'abans de l'esclat del cisma d’Occident (1378), que dificultà més endavant l'accés dels frares catalans a les universitats italianes-i que després sojornà cinc mesos a Sicília, camí de Tunis, on es convertí a l'islam. ${ }^{4}$ A Bolonya o a Sicília Turmeda hauria pogut conèixer no solament la Commedia de Dante i l'ús abundant que en feien els seus confrares (Gómez 20I4: I45-55), sinó també les laude de Iacopone da Todi o l'anònima Dottrina dello schiavo di Bari, font principal del seu Llibre de bons amonestaments (Tunis, 1398). En l'única part que no és adaptació de la Dottrina-l'elogi satíric dels diners-, ${ }^{5}$ Turmeda recull dos jocs de paraules que podria haver espigolat, significativament, en el registre més invectiu de Dante:

Diners fan vui al món lo joc,

e fan honor a molt badoc;

a qui diu "no" fan-li dir "hoc".

Vejats miracle! (Olivar ed. 1927: 154.2I-24)

Dante també havia denunciat l'acceptació de suborns i la prevaricació dels consellers de la ciutat de Lucca evocant una sentència de Lucà (Phars. X, 408: "Ibi fas, ubi maxima merces") esdevinguda proverbial:

... a quella terra, che n'è ben fornita:

ogn'uom v'è barattier, fuor che Bonturo;

del no, per li denar, vi si fa ita. (Inf. XXI, 40-42) ${ }^{6}$

Poc més avall, Turmeda es refereix per metonímia als florins, que porten gravada l'efígie de sant Joan Baptista, patró de Florència (cal retocar, doncs, la puntuació d'Olivar, que, interpretant un altre joc de paraules, editava "sent jo ha'n”):

Si vols haver bé e no dan

per advocat té sent Johan.

Totes coses per ell se fan,

en esta vida. (Olivar ed. 1927: I55.I-4)

Dante anomena el florí "la lega suggellata del Batista" (Inf. XXX, 74), i en la seva invectiva contra la simonia del papa Joan XXII, després de pregar que la justícia divina “un’altra fiata omai s’adiri /

4. Per al relat, vegeu la traducció d’Epalza I978, ıo6-ıo. Els estudis de Turmeda a Bolonya i a París s’afirmen indirectament en la Disputa de l'ase, que la Tuhfa no esmenta (Epalza r978: 36 ; I994 [1971]: I5-I7). Vegeu també Riquer I984 [r964]: 2, 446-47. El nom de Turmeda ha estat inclòs en el cartulari de l’Estudi de Sant Francesc de Bolonya només a partir del seu propi testimoniatge (Piana I970: $77^{*}-78^{*}$ ). Tampoc no consta, d'altra banda, cap exemplar de la Commedia en l'inventari de la biblioteca franciscana de Bolonya de I42I (Frati i89o).

5. Riquer (I984 [I964]: 2, 454-60, esp. 458) compara aquesta secció amb el Versus de nummo (“In terris summus rex est hoc tempore nummus") dels Carmina Burana.

6. Cito sempre la Commedia segons l’edició de Petrocchi r994 [ı966-67]. 
del comperare e vender dentro al templo / che si murò di segni e di martiri” (Par. XVIII, I2I-23), s’adreça explícitament al papa subratllant la seva obsessió pels florins. Els esmenta mitjançant una perífrasi relativa a sant Joan Baptista ("colui che volle viver solo / e che per salti fu tratto al martiro"), que una simple nota interlineal hauria pogut aclarir: ${ }^{7}$

Ma tu che sol per cancellare scrivi,

pensa che Pietro e Paulo, che moriro

per la vigna che guasti, ancor son vivi.

Ben puoi tu dire: "I' ho fermo 'l disiro

sí a colui che volle viver solo

e che per salti fu tratto al martiro,

ch’io non conosco il pescator né Polo.” (Par. XVIII, I3O-36)

El caràcter proverbial d'aquests paral-lelismes -i també d'altres $-{ }^{8}$ no ens permet d'afirmar que Turmeda conegués la Commedia, tot i que es tracta d'una possibilitat versemblant en un franciscà de tendència reformista o espiritual format a Itàlia.

Les vies d'entrada de la Commedia en terres catalanes foren segurament diverses, extraordinàriament primerenques en el context europeu, no sempre documentables i, de vegades, lligades a circumstàncies personals més o menys atzaroses. En les pàgines següents intentaré, però, de recollir els primers indicis segurs de la difusió de la Commedia en la cultura catalana i a l'entorn de la dinastia reial del Casal de Barcelona, incorporant les aportacions més recents de la crítica i proposant una interpretació històrica que relaciona el coneixement de Dante no solament amb unes personalitats individuals i intel-lectualment excepcionals, sinó també amb una política cultural que emanava de la casa reial.

\section{Dante i els lectors del Roman de la Rose}

El primer indici segur d'una lectura de la Commedia a la Corona d'Aragó és un lleu ressò de la veu de Francesca (Inf. V, I2I-23: "Nessun maggior dolore / che ricordarsi del tempo felice / nella miseria”) perceptible en el Llibre de Fortuna e Prudència de Bernat Metge (vv. 46o-63; Cabré ed. 2OIO: IO8):

Lo major dolqu.om pot soffrir

és, a mon juy, haver usat

d'onor e de felicitat

e qu·om se’n veja puys desert.

7. Al segle XIV ja devia ésser habitual d'al·ludir al florí d'or amb la metonímia de sant Joan Baptista i/o sant Joan Crisòstom; cf. Boccaccio, Decameron I, vI, 8-9: “A che lo ’nquisitore santissimo e divoto di san Giovanni Barbadoro disse: [...]. E in brieve tanto lo spaurí, che il buono uomo per certi mezzani gli fece con una buona quantità della grascia di san Giovanni Boccadoro ugner le mani (la quale molto giova alle infermità delle pistilenziose avarizie de' cherici, e spezialmente de’ frati minori, che denari non osan toccare) ...” (Branca ed. I992 [I980]: I, 96-97); Sacchetti, Trecentonovelle, CXXVIII: “E 'l vescovo si portò poi sí, e con la sua prudenza, e con la virtú di Santo Giovanni Boccadoro ...”, i cXCVIII: "che adorava dinanzi a santo Giovanni Boccadoro" (Faccioli ed. I970: 336 i 592).

8. Lola Badia (I997: I4) exclou la influència de l’autoencàrrec de Dante sobre el de Turmeda en les Cobles de la divisió del regne de Mallorca (I398), i la coincidència en alguns tòpics de la literatura política tampoc no permet de conjecturar cap influència de la conversa entre Dante i Ciacco sobre la divisió de Florència i la seva causa, l'enveja (Inf. VI, 34-93, esp. vv. 49-50, 6I-63 i 74-75). 
Com anota Lluís Cabré, el passatge implica una superposició d'estímuls que provenen del model immediat, l'Elegia d'Arrigo da Settimello (I, 29-30: "O felix qui non est usus prosperitate! / Nam venit ex sola prosperitate dolor”), i del seu antecedent clàssic, la Philosophiae consolatio de Boeci (II, pr. 4, 2: "nam in omni adversitate fortunae infelicissimum est genus infortunii fuisse felicem"), però l'adjectiu major fa palès que "Metge rediu el motiu de l'Elegia amb el record boecià de Dante" (Cabré 2OIO: IO8, i 34-35). Altres reflexos textuals i estructurals, assenyalats i debatuts durant un segle de crítica, resulten menys evidents. ${ }^{9}$ Sobretot a propòsit del vell tot despullat que empeny Bernat mar endins, després de fer-lo pujar en una barca perquè li allargui un abrigall (vv. 48-89), la crítica ha suggerit diverses identificacions amb personatges de la tradició clàssica amb un paper més o menys destacat en la Commedia, com ara Caront, Cató d'Útica, Tirèsies o, fins i tot, el pescador Amicles de la Pharsalia $\left(\mathrm{V}, 5^{\mathrm{I}} 5^{-60}\right)$ de Lucà. ${ }^{\mathrm{IO}} \mathrm{A}$ la vista de la vellesa invàlida del personatge, de les seves escasses possessions -un anap ('copa'), un cantell de pa, un tabà ('mantell') i un capell de cànem per al sol- i de la lliçó moral amb què censura l'avidesa de diners de l'autor, tot refusant

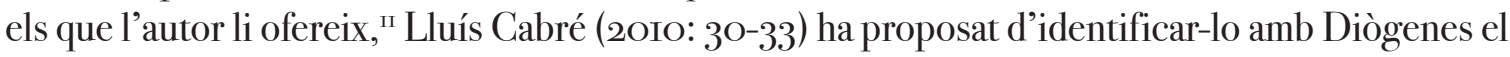
Cínic, al·legant, entre altres paral-lels, una glossa molt significativa de l'Ottimo commento (In Inf. IV, I37):

Diogenes ebbe per suo vestire uno mantello doppio per lo freddo, una tasca per celliere, e seco la portava, e portava uno bastone per sostenere il suo già debole corpo con lo quale già vecchio er' ausato di sostenere i suoi membri; abitò nelli limitari delle porte, e nelli antiporti delle cittadi, confessando il vero e riprendendo li vizii; e abitò in una botte, la quale elli volgeva; la state chiuso contra il sole, e il verno si volgea contro il meriggio, e sollazzevolmente diceva ch'aveva casa volubile; e portava seco un nappo di legno per bere, e vedendo un dì uno fanciullo bere con le palme delle mani, ruppe in terra il nappo, e disse: io non sapea che la natura avesse seco il vaso da bere. Mai non piegò del vigore dell'animo. Alessandro venne a lui dimorante nella botte, tempo era di verno, e offerseli ciò che li volesse dimandare: chieseli, ch'elli si levasse dal sole, e altro non volea da lui; e che egli era più ricco di lui, però che egli era più quello ch'egli non volea, che quello che Alessandro potea dare. (Torri ed. I829: I, 6o)

El paral-lel no és concloent, però és molt convincent i podria constituir la primera evidència d'un

9. La influència de la Commedia sobre el Llibre de Fortuna e Prudència, suggerida per Farinelli (I9O2-I9O5: 20-37) i desestimada precipitadament per Post (I908: 50), restà sub iudice-i pràcticament reduïda al possible record boecià de Francesca- després de la darrera síntesi de Farinelli (I922: 78). Marco Boni (I967: 392) insistí almenys en aquest ressò: “mi sembra veramente un'eco del nessun maggior dolore di Dante, perché in Boezio la parola 'dolore’ non ricorre per nulla. A mio parere il Liber [sic] de Fortuna e Prudència può esser quindi considerato una testimonianza assai probabile della conoscenza della Commedia di Dante già a quel tempo da parte del Metge." Encara no era possible sospitar la presència del mot dolor en Arrigo da Settimello, una font identificada per Fleming (I982). Nepaulsingh (I977: 209-I2) afirmà amb nous arguments la influència de Dante en el conjunt de l'obra, indicant un seguit de paral.lelismes amb el Purgatorio avaluats i no confirmats per Cabré (2OIO: 35): "No podem descartar que Metge tingués a la memòria l'inici del Purgatorio, però no sembla que aquest text s'hagi de considerar una font estructural del LFP."

Io. Per a la discussió d'aquestes propostes, amb la bibliografia relativa, remeto a Cabré 20ıо: 29-35, esp. nn. 4I i 54 .

II. $C f$. vv. 48-77: "Aprés un pauch viu que sesia / prop una barcha un hom vell, / tot despulhat, ab un capelh / de cànem gros sobre son cap; / en l’una mà tench un anap / e·n l'altra un cantelh de pa. / E cant me vi fortment cridà, / disent: 'Sényer, mercè m’ajats!' / 'En prom’, dix eu, 'què demandats? / Volets, per Dieu, algun diner?' / 'No, sényer, que major master / l'avets vós', dix ell, ‘que·n sercats / e cascun jorn imaginats / com ne porets esser fornit; / ez yeu no trop major delit / sinó quant no hay què despendre, / car suy cert que no pot dexendre / lo meu stat en pus baix loch; / e vós temets plus que gran foch / so que deuríets desigar. / Mas prech-vos que·m vullats donar / -e seré-us tostemps obligat- / un tabà qu·ay anit lexat / en esta barcha per oblit / (ab la qual arribey anit / en aycest loch ab gran tempesta), / e donar-m'ets tota la resta / que pocesesch en aquest món, / car, per ma fe, ten robat son / que no m'i poria levar.'” (Cabré ed. 20Iо: 87-88). 
comentari dantesc en terres catalanes. En tot cas, el manuscrit de la Commedia que Bernat Metge coneixia podia incloure fâcilment alguna mena d'aparat exegètic.

Metge parteix de la platja de Barcelona en el seu viatge al-legòric a l'illa de Fortuna l'i de maig de I38I. Nascut pels volts de I348, tenia aleshores uns trenta-tres anys, i ja en feia deu que havia ingressat al servei de la Cancelleria Reial de la mà del seu padrastre, Ferrer Saiol, protonotari de la reina Elionor. Des del I5 d'abril de I37 I fins a la mort de la reina, el 20 d'abril de I375, Metge s'havia exercitat a la seva escrivania com a ajudant de registre. Tot seguit passà, amb l'ofici d'escrivà, a la cancelleria del primogènit Joan, encara duc de Girona, rei d’Aragó des del 5 de gener de I387, i el I390 ascendiria finalment al càrrec de secretari reial. L'ampli horitzó cultural que s'albira en la seva obra literària és, en part, un reflex d'aquest perfil professional i d'una carrera administrativa sempre lligada a la cancelleria i a la cort. ${ }^{12}$

És prou sabut que Bernat Metge fou també pioner en la lectura, l’adaptació i la imitació de Petrarca i Boccaccio. No gaire després de la primera menció explícita de Petrarca en una epístola llatina de Pere Despont, secretari del príncep Joan, datable entre I386 i I387 (Riquer 1959: * 49*5I; Rico I983: 267-73; Coroleu 20I2: 7-IO), Metge es confessava devot de Petrarca i en traduïa la Griseldis en la seva Història de Valter e Griselda (I308?), adreçada a Isabel de Guimerà, muller de Gispert de Guimerà (I372) i filla de Berenguer de Relat, mestre racional del rei Pere i abans tresorer de la reina Elionor (Riquer i959: ${ }^{*} 45^{-{ }^{*}} 5^{8}$ ). Com ha demostrat Lluís Cabré (2OI2), en aquest text Metge adapta el model epistolar de Petrarca (Seniles XVII, 3-4) amb els ulls posats en la novella original de Boccaccio (Decameron $\mathrm{X}, \mathrm{IO}$ ), però ho fa imitant - -i superant- una recentíssima traducció francesa ( ${ }_{3} 3^{8} 7$ ) de Philippe de Mézières, que fou conseller de Carles V de França i tutor de Carles VI ("Le miroir des dames mariées, s'est assavoir de la merveilleuse pacience et bonté de Griseldis, marquise de Saluce", Livre de la vertu du sacrement de mariage IV, 4-IO). Fins i tot els elogis que Metge dedica a Petrarca són un ressò del pròleg de Mézières (IV, 3). De tot plegat, Cabré n'ha tret conclusions importants per a descriure i comprendre no solament el petrarquisme de la cancelleria de Joan I i la recepció quasi immediata de novetats franceses procedents de les corts de París i Berry, sinó també algunes constants en la tècnica compositiva de Bernat Metge: practicant una translatio no merament lingüística, Metge manipula creativament les seves fonts llatines per adaptar-les a l'horitzó cultural dels seus lectors cortesans, i ho fa imitant el precedent d'altres adaptacions romàniques. En efecte, pocs anys abans, en el disseny al-legòric del Llibre de Fortuna e Prudència, les fonts llatines havien estat l'Anticlaudianus d'Alain de Lille i l'Elegia d'Arrigo da Settimello, amb el rerefons ineludible de Boeci, mentre que el principal model romànic catalitzador de l'adaptació - a més de La faula de Guillem de Torroella, la Ventura de Vicenç Comes i potser el Remède de Fortune de Guillaume de Machaut- fou el Roman de la Rose de Jean de Meun (Nepaulsingh I977; Cabré 2006 i 2OIO: 24-4I).

Una de les claus d'aquesta obertura als corrents culturals provinents de França fou, evidentment, el matrimoni en segones noces del primogènit Joan amb Violant de Bar, el 29 d'abril de I380 (Riquer I959: *22- 24 ; Cabré-Ferrer 20I2). La jove Violant, filla del duc Robert de Bar, neboda del rei Carles V de França i també dels ducs Joan de Berry i Felip l’Ardit de Borgonya, comptava llavors uns quinze anys, però havia rebut una exquisida educació literària. És possible, com s'ha argumentat no fa gaire (Cabré-Ferrer 2012: 220), que ja posseís aleshores un exemplar del Roman de la Rose, potser el mateix que el I5 de novembre de I382 reclamava a l'infant Martí, duc de Montblanc, des de Sogorb; en tot cas, el 8 de març de I383 ella mateixa agraïa al seu oncle Joan de Berry la tramesa d'un - altre? - exemplar de gran qualitat (Vielliard I93O: 30-3I). Una profusa

I2. Per a la biografia i la formació de Bernat Metge, vegeu sobretot Riquer I959: * II- ${ }^{*}$ I96; Cingolani 2002 i 2006 : I3-37; Cabré 2OIO: 9-20, i els estudis recollits en Cabré-Coroleu-Kraye ed. 2012. 
documentació d'arxiu testimonia la intensitat de la circulació de llibres per una via que donava accés immediat tant a la biblioteca fundada per Carles $\mathrm{V}$ a la Torre del Louvre el I368 com a les seves ramificacions, sobretot a partir de la coronació de Carles VI (I380), que permeté la dispersió d'exemplars entre els membres de la família (Cabré-Ferrer 20I2: 2I7-I8). Amb la difusió de textos i traduccions en llengua francesa, les corts de França també difonien un model cultural de prestigi en llengua vulgar (Cabré-Ferrer 2OI2: 228).

Aquest model pogué beneficiar indirectament l'acceptació i el prestigi cultural d'una obra en vulgar com la Commedia a la cort d'Aragó, però d'antuvi no sembla gaire probable que el contacte familiar amb les corts de França fos una via de difusió de les obres de Dante -ni encara menys dels seus comentaris- a l'entorn de Joan I i Violant de Bar. La fortuna de Dante a la França medieval fou més aviat escassa -molt més que la de Petrarca i Boccaccio, fins i tot en vulgar-, i gairebé totes les evidències que en posseïm són lleugerament posteriors als primers ressons de la Commedia en la literatura catalana del segle XIV. Les notícies més antigues relatives a manuscrits daten del segon terç del $\mathrm{XV},{ }^{13} \mathrm{i}$ les primeres traduccions franceses, per bé que nombroses, són totes del segle XVI, en què proliferen també les edicions i les imitacions poètiques. ${ }^{\text {II }}$ Pel que fa a influències, al-lusions o mencions explícites, el primer testimoniatge de la Commedia a França és el ressò d'una diatriba dantesca contra els genovesos en el Songe du vieil pèlerin (I389) de Philippe de Mézières. ${ }^{15}$ L'extraordinària activitat militar i diplomàtica que Mézières havia desplegat arreu d’Itàlia, a la Mediterrània oriental i a la cúria papal d'Avinyó - on conegué Petrarca-, així com la seva posterior incorporació al consell de Carles V -al costat de personatges com Nicole Oresme-, fan molt difícil de precisar l'origen i l'abast del seu coneixement de la Commedia. Una altra invectiva dantesca ressona en el Livre de l'Espérance que Alain Chartier deixà inacabat a la seva mort (c. I430): Chartier, que havia estat ambaixador a Venècia el I425, després d'una altra

I3. No consta cap exemplar de la Commedia a la biblioteca de la Torre del Louvre (Delisle r9O7: $3^{*}-2 \mathrm{I} 6^{*}$ ) ni a la del duc de Berry (Delisle I9O7: 2I $7^{*}-326^{*}$ ), excepte un manuscrit de mà italiana del tercer quart del Xv (París, Bibliothèque Nationale de France, it. 72) que pertangué al jove Carles de França (I446-72), duc de Berry, Normandia i Guyenne, i germà petit del rei Lluís XI (Auvray I892: 24-25; Delisle 19O7: 3I7* doc. 296 bis). Joan II de Borbó (I426-88) també posseí un manuscrit de mà italiana de la primera meitat del XV (París, Bibliothèque Nationale de France, it. I470, amb la nota "Iste liber est domyny Johannis de Bourbonnio, commitis Clarimontis"), que l'abril de I453 regalà a Louis de La Vernade, cavaller i jutge del Forez ("Et preffatus dominus meus comes ipsum librum dedit mihi Ludovico de La Vernade, militi et presidenti Forensi, Turonis, in mense aprilis, anno Domini MCCCCLIII, ante Pascha”) (Auvray I892: 39-40). En l’inventari de llibres del duc Amadeu VIII de Savoia, aixecat el I434, quan es retirà a la vida monàstica i cedí el govern al seu fill Lluís, hi consten Boccaccio i Dante: "Liber centum novelarum in lombardo e il libro de Dant" (Borghezio-Fasola I92I; Branca I958-9I: 2, I38). René d’Anjou (I409-80), rival d’Alfons el Magnànim al regne de Nàpols, també posseí un “Dante de Fleurance” avui perdut (Durrieu I92I: 2I9).

I4. Abans de la traducció en vers del conseller i almoiner reial Balthazar Grangier (París, George Drobet, I596-97), dedicada a Enric de Navarra, i de la traducció del darrer cant del Paradiso de Guy Le Fèvre de la Boderie (I578-82), François Bergaigne havia ofert una traducció del Paradiso en decasílllabs a la reina Clàudia, primera muller de Francesc I, entre I5I4 i I524 (Morel ed. I897: 589-603); s'ha conservat també una traducció anònima de l'Inferno en alexandrins (Morel ed. I897: 3-I9I; Camus I9OI) i una altra traducció integral en alexandrins, anònima, de mitjan XVI (Morel ed. I897: 193-586). Al segle XVI, des del I506 (Simone 1965: 35), també són destacables les nombroses impressions lioneses de la Commedia, especialment les de Giovan de Tournes (I547) i Guillaume Rouillé (I55I, I552, I57I i I575). Per a la influència de Dante en la cultura francesa del segle XVI, vegeu Farinelli r9o8; Simone I968: 59-74 i I5I-68; MathieuCastellani 2004.

I5. Badel I97I: 334; Di Stefano I974: I65-66. Cf. Inf. XXXIII, I5I-53: "Ahi Genovesi, uomini diversi / d'ogne costume e pien d'ogne magagna, / perché non siete voi del mondo spersi?”; Philippe de Mézières, Songe du vieil pèlerin I, 39: "ceste generation genevoise, de tous ses voisins appellee perverse, laquelle selon le livre des docteurs devroit estre du monde destruite et entierement dispersee" (Coopland ed. I969: I, 296); Di Stefano (I974: I65) ha remarcat que la lliçó “le livre des docteurs" del ms. $A$ és un error, com també ho és "le livre David” de $C$, mentre que $B$ reporta la lliçó correcta: "le livre de Dant". 
ambaixada prop de l'emperador Segimon i del papa Martí V, carrega contra els vicis del clergat i exculpa, en canvi, l'emperador Constantí de la corrupció de l’Església que Dante li retreu per la seva donació funesta. ${ }^{16}$ Mézières podria haver llegit poc o molt la Commedia, i Chartier fins i tot amb l'assistència d'un comentari, potser després de la seva ambaixada veneciana (Di Stefano 1974: I64 n. I i r67). Més dubtós és el cas de Laurent de Premierfait, secretari del duc de Berry. En la segona redacció ampliada (I409) de la seva traducció francesa del De casibus de Boccaccio (Des cas de nobles hommes et femmes, Ia red. de I400), Laurent amplifica una menció fugissera de Dante (IX, 23) al-ludint al seu exili i a la seva presumpta estada a la universitat de París - una notícia difosa per Giovanni Villani (Croniche IX, I36) i Boccaccio (Trattatello, ra red., 75; 2a red., 56; Esposizioni, "Accessus", 34; Genealogie XV, 6)-, i a més a més atribuint-li la intenció d'emular el Roman de la Rose (Di Stefano I974: I62-63; Richards I98г: 74-77; I985: IIо-II).

Fet i fet, el millor testimoniatge d'una lectura de la Commedia en la França del tombant de segle, excepcional per les seves implicacions ideològiques i literàries, és el que proporciona Christine de Pizan entre I4OI i I405, en relació amb la controvèrsia sobre el Roman de la Rose i amb la seva pròpia ubicació com a escriptora en la tradició francesa. ${ }^{17}$ Christine de Pizan, quasi coetània estricta de Violant de Bar, nasqué a Venècia el I365, però el seu pare, Tommaso di Benvenuto da Pizzano, estudiant i docent d'astrologia i medicina a la universitat de Bolonya, i conseller de la República de Venècia, s’incorporà el I369 a la cort de Carles V com a metge i astròleg del rei (Nicolini I94I; Willard I980). En aquesta data, o no gaire després, pogué arribar a la cort reial de França el manuscrit de la Commedia en què Christine de Pizan llegia Dante ${ }^{18}$ Christine s'educà en una cort lletraferida, sota el poderós ascendent del Roman de la Rose, i tingué lliure accés a la biblioteca del Louvre. A començament de I380 es casà, a quinze anys, amb el secretari reial Étienne de Castel, que morí el I390, dos anys després de la mort del pare. Fou cap a la fi del segle que inicià, pels volts dels trenta anys, la seva activitat pública com a escriptora. L'estiu de I 4OI adreçà al secretari reial Jean de Montreuil una epístola molt crítica amb els elogis que ell mateix havia dispensat al Roman de la Rose en un tractat avui perdut: el punt de vista de Christine, rebutjat pel secretari reial Gontier Col i pel seu germà, el canonge Pierre Col, rebé el suport del canceller de la universitat de París,

I6. Di Stefano I974, esp. I59 i I63-65. Cf. Inf. XIX, II5-I7: “Ahi, Costantin, di quanto mal fu matre, / non la tua conversion, ma quella dote / che da te prese il primo ricco patre!”; Alain Chartier, Livre de l'Espérance VIII, 11. I87-202 (Rouy ed. I989: 56): “Et tu, Dante, poete de Florence, se tu vivoyes adés, bien auroys matiere de crier contre Costentim [sic], quant, ou temps de plus observee religion, le osas reprendre, et lui reprouchas en ton livre qu'il avoit getté en l'Eglise le venin et la poison dont elle seroit desolee et destruicte, pour ce qu'il donna premier a l'Eglise les possessions terriennes, que aucuns aultres auctorisiez docteurs lui tournoient a louenge et a merite. Qui te mouvoit a si catholique empereur envahir et blasmer fors les scismez, lez discors, les desordonnances et iniquitez que tu voyes naistre en l'Eglise par l'abondance dez richesses du clergié, qui sont nourritures de ambition et d'envie, ainsi que la gresse est nourrissement du feu, et l'uyle de la flambe? Je ne te acorde pas que pour l'abus dez recevans soit frustee la charité du donneur. Et, se les cleres ne puent abuser des possessions sans damnation, il ne s'ensuyt pas que Costentin ne fist chose de bonne entente le donner sans pechié.” El mateix Di Stefano (1974: I66-67) suggereix, amb cautela, una altra possible influència d'Inferno XXXII en el capítol VIII del Livre de l'Espérance.

I7. Vegeu Farinelli r905; Batard 1975; Richards I985: IOI: "none of Christine’s contemporaries in France were even reading Dante, much less influenced by him”, i també p. III: “Christine’s reception of Dante stems from an independent and, for the France of her day, almost idiosyncratic attitude toward the Italian poet. [...] While Christine’s attempt to dissociate the Commedia from the Rose ignores significant affinities between the two works, it nevertheless underscores the astuteness of Christine's understanding of the Commedia and establishes her position as a significant -and hitherto underestimated- interpreter of Dante."

I8. Vegeu Petroni r967: 384-86, esp. 385: "educatosi a Bologna al culto dantesco, tale culto trasmise alla propria figlia, che a sua volta se ne fece divulgatrice in Francia"; Richards I985: IOI: "one can say from the frequency and variety of Christine's Dantean allusions that she must have had a copy of the Commedia at her disposal, most likely taken from the library of her father Tommaso da Pizzano". 
Jean Gerson. Al final del debat, en una resposta a Pierre Col (2 d'octubre de I4O2), que havia lloat la representació de l’infern i el paradís en l'obra de Jean de Meun, Pizan li recomana que llegeixi Dante, tot i que desconfia -no pas sense mordacitat- que pugui entendre l'estil incomparable i sublim de l'italià. ${ }^{19}$ Poc abans, en l'Epistre Othea (I4OI), Christine havia evocat la descripció dantesca de Minos, el jutge infernal (Batard I975: 272; Parussa ed. 1999: 388)..$^{20}$ A part d'altres possibles ressons implícits (Richards I985: IOI-IO2 n. 5), Christine menciona Dante en tres títols dels anys I4O2-I4O5. En Le Livre de la mutacion de Fortune (I4O4) Dante encapçala la llista d'autors italians (Cecco d'Ascoli, Cino da Pistoia) que denuncien el conflicte secular entre güelfs i gibel-lins: l'autora cita aquí la invectiva irònica de Dante contra Florència (Inf. XXVI, $\mathrm{I}-3$ ), ${ }^{2 \mathrm{r}}$ mentre que en La Vision Christine o Le Livre de l'advision Cristine (I4O5) s'adreça al personatge al-legòric de Frau al-ludint a la interpretació al-legòrica de Geríon al cant XVII de l'Inferno. ${ }^{22}$ Tots dos casos revelen familiaritat amb la poètica dantesca, encara més evident en Le Chemin de long estude: una visió en somni, datada el 5 d'octubre de $\mathrm{I}_{402}$ (vv. I85-88), en què Christine assumeix Dante com a model literari personal, alternatiu a Jean de Meun (Merkel I92I; Brownlee 1995). El títol de l'obra ja remet a una invocació dantesca de Virgili en el cant proemial de l'Inferno, citada explícitament, i també repetida com a talismà intel-lectual (Brownlee I995: I25-26, I29-30). ${ }^{23}$ A Christine, certament, és

I9. Cf. Débat III, IV (“A maistre Pierre Col, secretaire du roy nostre sire”), 11. 868-76 (Hicks ed. I977: I4I-42): "Mais se mieulx vuelz oïr descripre paradis et enfer, et par plus subtilz termes plus haultement parlé de theologie, plus prouffitablement, plus poetiquement et de plus grant efficasse, lis le livre que on appelle le Dant, ou le te fais exposer pour ce que il est en langue florentine souverainnement dicté: la oyras autre propos mieux fondé plus subtilment, ne te desplaise, et ou tu pourras plus prouffiter que en ton Romant de la Rose, -et cent fois mieux composé; ne il n’y a comparison, ne t'en courouces ja." Segons Richards (I985: IO2-IO7), alguns dels conceptes d'aquesta resposta es fan ressò del debat italià sobre la poetica theologia; a parer meu, s'hi percep un ressò de Boccaccio, Genealogie XV, 6 : "Qualis fuerit, inclitum eius testatur opus, quod sub titulo Comedie rithimis, Florentino ydiomate, mirabili artificio scripsit. In quo profecto se non mythicum, quin imo catholicum atque divinum potius ostendit esse theologum; et, cum fere iam toto notus sit orbi, nescio utrum ad celsitudinem tuam sui nominis fama pervenerit” (Romano ed. I95 I: 2, 76I).

20. Epistre Othea 4, "Glose .iiij.": "Minos, comme distrent les poetes, est justicier d'enfer, sicomme on diroit prevost ou baillif, et devant lui sont amenees toutes les ames descendans en ycelle valee, et selon que elles ont desservi penance, et autant de degrez comme il veult que elles soient mises ou parfont, il tourne sa queue entour soy" (Parussa ed. I999: 207-208; la cursiva és meva); $c f$. Inf. V, 4-I2: “Stavvi Minòs orribilmente, e ringhia; / essamina le colpe ne l'intrata; / giudica e manda secondo ch'avvinghia. / Dico che quando l'anima mal nata / li vien dinanzi, tutta si confessa; / e quel conoscitor de le peccata / vede qual loco d'inferno è da essa; / cignesi con la coda tante volte / quantunque gradi vuol che giù sia messa" (la cursiva és meva).

2I. Cf. Le Livre de la mutacion de Fortune, vv. 4645-49: "Dant de Florence, le vaillant / Poete, qui tout son vaillant / Perdi pour cel estrif grevable, / En son bel libre tres notable / En parla, moult en les blasmant”, i vv. 4663-70: "Et Dant, en parlant a Flourence, / Ou il avoit sa demourance, / En maniere de moquerie / Lui dit que 's'esjouïsse et rie, / Car sur terre et sur mer se batent / Ses esles et meismes s'embatent / Jusqu'en Enfer, en quel maison / A de ses citoiens foison"” (Solente ed. 1959-66: 2, I5-I6 i I6).

22. Cf. La Vision Cristine, XVI: "ne te vid pas en fourme dorrible serpent / a longue queue iadis le tres sage / poete Dante de Florence sus les palus / denfer quant la le convoya Virgile / si comme en son livre le recite?” (Towner ed. I932: $90)$.

23. Cf. Inf. I, 82-87: “O de li altri poeti onore e lume, / vagliami 'l lungo studio e 'l grande amore / che m'ha fatto cercar lo tuo volume. / Tu se' lo mio maestro e 'l mio autore, / tu se' solo colui da cu' io tolsi / lo bello stilo che m'ha fatto onore"; Le Chemin de longue estude, vv. II27-46: “... Fors en tant que bien me recorde / que Dant de Florence recorde / en son livre qu’il composa / Ou il moult beau stile posa, / Quant en la silve fu entrez / Ou tout de paour ert oultrez, / Lors que Virgile s'aparu / A lui dont il fu secouru, / Adont lui dist par grant estude / Ce mot: 'Vaille moy lonc estude / Qui m’a fait chercher tes volumes / Par qui ensemble accointance eumes.' / Or congnois a celle parole / Qui ne fu nice ni frivole / Que le vaillant poete Dant, / Qui a lonc estude ot la dent, / Estoit en ce chemin entrez, / Quant Virgile y fu encontrez / Qui le mena par mi enfer, / Ou plus durs lïens vid que fer", i vv. I388-96: "Mais tout adés me souvenoit / Du bon mot qui vault en tel cas, / Car quant j'estoie en un fort pas / Ou a passer je fusse rude, / Disant: 'Vaille moy lonc estude!' / Alors passoye seurement, / Sans avoir nul encombrement, / Non obstant celle terre sure / Et du souleil la grant arsure" (Tarnowski ed. 2000: I54-I56 i I70). 
la Sibil.la que li fa de guia, com a remota antecessora en un llinatge intel-lectual femení; però tot el passatge de la seva aparició (vv. 45- ${ }^{\mathrm{I}}$-72) és modelat a partir dels dos cants proemials de l'Inferno, així com el seu viatge al Parnàs (vv. 7 ${ }^{\mathrm{I}} 3$-II $7 \mathrm{O}$ ) imita els llimbs-Elisis de cant IV, etc.

Podem afirmar, per concloure, que almenys un manuscrit de la Commedia degué arribar a París, prop de la cort reial de França, entre I369 i I380; Philippe de Mézières cita i menciona Dante el I389; Christine de Pizan oposa Dante a Jean de Meun i el recomana a Pierre Col el I4O2, alhora que l'assumeix explícitament com a model intel-lectual personal i el reivindica a la cort reial entre I4OI i I4O5. A la cort de Berry, el I4O9 Laurent de Premierfait incorpora a la redacció ampliada de la seva traducció del De casibus una semblança biogràfica de Dante que subratlla la importància determinant del seu presumpte viatge a França, testimoniat per Boccaccio. Tot indica que el nom de Dante era conegut a la cort reial de França a les darreres dècades del segle XIV i que Christine de Pizan contribuí al seu prestigi com a model alternatiu al Roman de la Rose a la primera dècada del XV. La intervenció de Jean Gerson en la querelle del Roman de la Rose fa pensar que el ressò de la controvèrsia degué arribar a la universitat.

Precisament des del I4O4 havia freqüentat la universitat de París el mestre en arts barceloní Felip de Malla (c. I372-I43I), que hi rebé el títol de mestre en teologia el desembre de I4O.$^{24}$ L’inventari pòstum de la seva biblioteca (I43I) ens certifica que posseïa tant el Roman de la Rose com la Commedia. ${ }^{25}$ En els seus sermons al Consistori de la Gaia Ciència de Barcelona (I4I3) havia proposat als "trobadors estudiosos" els models de Dante, Jean de Meun i Arnaut Daniel, mestres immortalitzats per la fama en les tradicions italiana, francesa i trobadoresca. ${ }^{26}$ I els ressons de la Commedia són nombrosos tant en la seva predicació solemne (I4II) ${ }^{27}$ com en la primera part (I4I924) del Memorial del pecador remut, on recorda amb admiració Jean Gerson. ${ }^{28}$

24. Madurell i Marimon I963-64: 5OI-ı6; Perarnau I978: 60-8I; Pujol 20I5: 37O-76. Mentre estudiava a París, el rei Martí li encarregà diverses gestions davant el provincial dels celestins en relació amb la fundació d'un monestir al Palau Major; el 23 de març de I 408 predicava a Porto Venere prop del papa Benet XIII, que des de Savona li havia concedit la parròquia de Santa Maria de Pi el 23 de novembre de I4O7; de retorn a Barcelona, el rei Martí el nomenà “conseller e promotor dels negocis de la cort” el 7 de novembre de I408 (Madurell i Marimon I963-64: 50I; Perarnau I978: 60-6I).

25. Madurell i Marimon I963-64: 559, no. 30: “Item .I. libre scrit en pergamins a dos colondells mètrich en francés appellat Romans de la Rosa, ystoriat, ab les posts cubertes de cordovà vermell empremtat antich, ab los tenchadors de argent esmaltat"; 560, no. 40: "Item .I. libre scrit en paper, appellat Dant en ytalià, ab les posts cubertes de albadina blancha, ab II ${ }^{\text {os }}$ tencadors larchs".

26. "Viuit per famam magister Ioannes de Mehun in Frantia, qui scripsit Romantium de Rosa; uiuit inter nos Arnaldus Danielis; uiuit in Tuscia Dantes” (Pujol I996: 219-20); Arnaut Daniel és invocat per influència de Dante, Purg. XXVI (Pujol 1996: 195-96). Per a una anàlisi de les doctrines literàries que Bernat Metge i Felip de Malla proposen en relació amb el Consistori de la Gaia Ciència, vegeu Pujol ı994a, I994b i 1996.

27. Concretament, es fa ressò de Purgatorio I, 2 (“omai la navicella del mio ingegno") i Paradiso II, I-9, esp. 8-9 (“Minerva spira, e conducemi Appollo, / e nove Muse mi dimostran l’Orse”), en un sermó de santa Eulàlia predicat a Barcelona el I2 de febrer de г4ІІ: "Bé conec que tu vols navegar en la gran mar de predestinatió. Consell-te que en tan gran golf te metes en la nau de la Sglésya. Consell a tot christià que nos·s vulle fiar en la barcha de son fràgil enginy, car vents s'i mouen de grans temptacions qui leugerement fan les gents trabucar, les serenes de remor de opinions hi canten e cové les orelles tapar, car ací ha fallit lo cant dels philosophs, si bé a semblança del cigne se són perforçats de cantar en lur extrema vellesa, e la gran trompa de Tulli hi ha perdut lo so. Ací, dien los poetes, spira lo deu Apollo; ací concorren Minerva e les ·ix. [ms. -ii.] Muses; ací totes les arts del famós mont Pernasus” (Pujol 1993-94: 278-8I i 287-88). En un altre sermó no datat, Pujol (20I5: 388) detecta un clar ressò de Purgatorio VI, 77 ("nave sanza nocchiere in gran tempesta"): "roman sense noixer la nau en gran tempesta".

28. Perarnau (1978: I20-22) atribueix a la Commedia un paper determinant en el pla de l’obra, a més d'assenyalar (II6 n. I4) algun possible ressò puntual (Par. XXX, 40). Pel que fa als ressons més evidents, vegeu Memorial del pecador remut, I, proemi, I54: "la naveta de la mia intel-ligència”, i II, 53-54: "la fràgil naveta de mon enteniment" (Balasch ed. I98I-86: I, 88 i II2, calquen Purg. I, 2 [Pujol 20I5: 388]); I, III, 66-68: "E lladoncs, assegurat un poc mi mateix, com home qui amb alè cansat, eixit de naufragi reposa un poc, e girant-se mira detràs si, trist e meravellat, diguí” (Balasch ed. 
Tot i que és possible que Felip de Malla ja conegués la Commedia abans d'arribar a París, és gairebé segur que en aquesta primera dècada del segle Xv la va llegir a la llum d'un altre clima cultural propiciat per Christine de Pizan. Per contra, no sembla pas que els ressons de la Commedia percebuts en el Llibre de Fortuna e Prudència (I38I) puguin provenir d'unes corts que, en efecte, no solament difongueren el model del Roman de la Rose -o la lírica de Guillaume de Machaut i d'Oton de Grandson-, sinó també textos i traduccions d'autors clàssics i humanístics com Petrarca o Boccaccio, però on el nom de Dante era molt poc conegut i els seus lectors molt comptats abans d'aquella data.

\section{${ }_{3}$ Dante, Petrarca i Boccaccio a Avinyó}

$\mathrm{U}_{1}$ na altra via oberta a la difusió internacional de novetats literàries i d’una alta cultura clàssica, patrística i humanística era la cúria papal d’Avinyó, tant abans com després del cisma de I378. Com a seu del poder pontifici, Avinyó no solament era residència permanent o destí freqüent d'autoritats, representants i alts funcionaris eclesiàstics, sinó també d'ambaixadors, legats, promotors i missatgers de grans corts i ciutats. Durant la segona meitat del segle XIV la monarquia aragonesa hi mantingué una intensa activitat diplomàtica, i un dels seus agents principals en diverses etapes d'aquest període fou l'erudit aragonès Juan Fernández de Heredia, gran mestre de Rodes, que morí a Avinyó el I396. L'estat de confusió creat arran del cisma, que recomanà al rei Pere el Cerimoniós una posició de neutralitat per a no comprometre la seva política mediterrània -concretament, les seves pretensions dinàstiques sobre territoris sotmesos a la jurisdició feudal de l'Església, com ara Sardenya o Sicília-, va afavorir, en canvi, la complicitat dels seus fills, Joan i Martí, amb el papa Climent VII i encara més amb el seu successor, el cardenal aragonès Pero Martínez de Luna, que assumí la tiara papal a Avinyó el 28 de setembre de I394 amb el nom de Benet XIII. Pocs mesos després, entre primers de febrer i primers d'abril de 1395, Bernat Metge integrà una ambaixada reial a Avinyó junt amb mossèn Roger de Montcada, camarlenc de la reina Violant, i Pere de Berga, promotor dels negocis de la cort, que ja havia acomplert diverses missions a la cort pontifícia al servei de Joan I (Riquer I959: ${ }^{*} \mathrm{II}^{-{ }^{*}} 74$ ). Aquest breu sojorn de dos mesos probablement imprimí un tomb decisiu en la trajectòria literària de Bernat Metge, oferint-li l'oportunitat d'enriquir el seu bagatge bibliogràfic amb alguns dels models més remarcables de la seva Apologia fragmentària (I395?) i, sobretot, de Lo somni (c. 1398):29 el Secretum i altres obres llatines de Petrarca (Riquer

I98I-86: I, I56, evoca Inf. I, I9, 22-24: "Allor fu la paura un poco queta [...]. E come quei che con lena affannata / uscito fuor de pelago a la riva / si volge ..." [Pujol 20I5: 388]); I, XII, 5I-52: "Dolça virtut d'oriental saffir, viva color" (Balasch ed. r98I-86: 2, 2O2, calc de Purg. I, I3: "Dolce color d'orïental zaffiro" [Montoliu I9I6: 4I; I923: 92 n. 2]); I, XVII, 822-4I (Balasch ed. I98I-86: 3, I47-48, ressò del viatge d'Ulisses d'Inf. XXVI, 9O-I42 [Pujol I993-94: 288-92]).

29. L'Apologia es presenta com un diàleg d'imitació petrarquesca amb un amic anomenat Ramon, identificable amb Ramon Savall, conseller de Barcelona en nombroses ocasions des del I378-79 i, en concret, conseller segon l'any I394-95; l'acció se situa a Barcelona en un període de pesta i el títol es justifica pel fet que hi "seran excusades o deffeses diverses impugnacions fetes contra veritat e satisfet a mos duptes per gràcia divinal”; per tant, Riquer (I959: 76-77*) en situa la ficció i la redacció a Barcelona entre l'abril i el juliol de I395-després que Metge tornà d'Avinyó i abans que es traslladés amb la cort a Mallorca per fugir d'una epidèmia-i la considera abandonada per un canvi de plans que culminarà en Lo somni. Cingolani (2OO2: I35-I39; 2OO6: I8) hi coincideix, desestimant la proposta d'una datació posterior (Rico I983: 83-84). Tot i que una datació entre i395 i l’inici de Lo somni sembla encertada, convé d'advertir que entre el gener i l'abril de i388 Metge fou objecte d'un primer processament -al qual s'ha vinculat la redacció del Valter e Griselda, inspirada en les Seniles de Petrarca (Riquer 1959: *4I-47) - i que la pesta també assolà Barcelona des dels primers mesos de I388 (Lo Forte Scirpo 2003: 52-54). Lo somni ja devia estar enllestit el dissabte 22 de març de I39., en què Ramon Savall i els consellers de Barcelona partiren per assistir a la coronació del rei Martí a Saragossa, 
I959: ${ }^{*} 75^{-*} 83$ ), tot i que ja en coneixia almenys les Seniles el ı388; alguns dels auctores clàssics i patrístics (Ciceró, Macrobi, Cassiodor) amb què Petrarca havia reconstruït el pensament platònic sobre la immortalitat de l’ànima (Torró 2002), ${ }^{30}$ i potser també el De mulieribus claris i la Genealogia deorum gentilium de Boccaccio. ${ }^{3}{ }^{3}$ Els dos textos de Petrarca -l'Africa i el De viris illustribus - amb què el dominicà Antoni Canals (c. I352-I4I9), capellà i confessor del rei Martí, bastí la seva versió de Lo parlament e batalla que hagueren Anibal e Scipió (I399/I4Io) també devien procedir d'Avinyó (Ferrer 2OI2: 52).32

L'àmplia presència de la Commedia -juntament amb l'Aeneis virgiliana i l'Hercules furens de Sèneca- rere la descripció de l'infern que fa Orfeu en Lo somni (III,iv,9-I8) és transparent i ben coneguda. ${ }^{33}$ En altres llocs també resulta més o menys probable. Els tres paral-lels que Cingolani addueix en les notes al llibre primer de Lo somni són molt difícils de valorar, car es refereixen a tres topoi de la literatura de visions: el temor davant l'aparició del rei (I,ii,4, 1l. 23-24; cf. Inf. XIII, 45 i 58, i XIX, 62), la impossibilitat de tocar o abraçar l'ombra de l'aparegut (I,iii, , , ll. III-I5; cf. Purg. II, 76 -84, i XXI, I30-32) i el recurs a la profecia post eventum (I,iii, , , ll. I22-29). Una proposta de reminiscència textual en l'íncipit del llibre tercer no sembla tan convincent com l'afinitat entre les expressions de penediment del rei Joan i del comte Ugolino. ${ }^{34}$ Cingolani també proposa un paral-lel

on restaren fins al dilluns 5 de maig (Schwartz-Carreras ed. I892: 76 i 77); Savall parlà a Martí I de l'obra de Metge: el 28 d'abril el rei li escrivia per demanar-li'n un exemplar, i el 7 d'octubre Bernat Metge partia cap a Saragossa com a

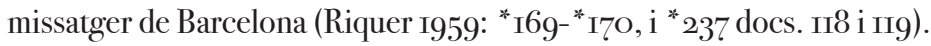

3o. Una altra font de Lo somni relacionada amb aquesta qüestió és el Liber de spiritu et anima (Gómez 2OIO), atribuït a sant Agustí en els inventaris de les biblioteques d’Urbà V (I369) i de Benet XIII a Peníscola (c. I420) (Faucon I886-87: I, I95, no. I2I8; II, 67, no. 258; 74, no. 3І

3. La Genealogia deorum gentilium ja consta en l'Inventarium librorum qui solebant esse in camera Cervi Volantis, nunc vero sunt in magna libraria turris (I379-80) del palau papal d’Avinyó (Faucon I886-87: 2, 30: “Item libellus geneologie (sic) deorum Johannis Bocacii, copertus de rubeo”); com diu Branca (I958-91: 2, 68), podria ésser el mateix manuscrit que s’enregistra en el catàleg de la biblioteca de Benet XIII a Peníscola (Faucon I886-87: 2, I39, no. 9I9: "Item Johannes Bocacii de geneologia (sic) deorum"). El De mulieribus claris no consta en els inventaris papals, però sí en biblioteques privades d'Avinyó com la del cardenal Pierre Blain el I4O7 (Branca I958-9г: 2, 59-60).

32. Com remarca Ferrer (2OI2: 43-44), es tracta de l'única traducció de l'Africa a qualsevol llengua fins al segle XVI, tot i que parcial (VII, 93-449 i 740-II30), i resulta extraordinàriament primerenca, atès que el poema, inacabat i ple d'anotacions a la mort de Petrarca, gairebé no es difongué fins a l'edició de Pier Paolo Vergerio (I395/96). L'Africa consta a la biblioteca de Benet XIII a Peníscola (Faucon I886-87: 2, I39, no. 9I6: "Item Affrica (sic) ejusdem, in papiro"). Bernat Metge també cita l'Africa en Lo somni a propòsit del somni d'Escipió narrat per Ciceró i comentat per Macrobi (I,v,28, ll. 460-6r: "lo qual reçita Tul-li en lo libre De re publica -e Patrarca semblantment en la Africa-, la exposició del qual ..."; Cingolani ed. 2006: I5I), però l'editor sospita que es tracta d'una glossa marginal molt primerenca, però probablement espúria, incorporada al text abruptament per un copista (Cingolani 2Oo6: IIO n. I3O). Riquer (ed. I959: 28I n.) percep en Lo somni (III,v,25: “O, de quanta caliya de tenebres són abrigats los desigs dels hòmens!"; Cingolani ed. 2006: 203-204) el ressò d'uns versos de l'Africa (I, 337-39: “O quanta, miseri, sub nube latetis! / Humanumque genus quanta caligine ueri / Voluitur!”), que apareixen precisament en un passatge relatiu a la immortalitat de l'ànima. Cingolani (2006: $3^{2}$ n. 46) ho posa en dubte i remet a Valeri Màxim (VII, 2, ext. r: "densissimis tenebris involuta mortalium mens, in quam late patentem errorem caecas praecationes tuas spargis!"), i tampoc no se'n pot excloure un record de Boeci (Phil. cons. III, 2, I3: "ad hominum studia [...] etsi caligante memoria").

33. Es tracta de la primera evidència d’influència dantesca reconeguda unànimement per la crítica (Sanvisenti r9O2:

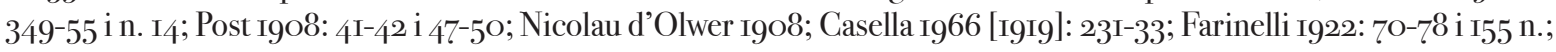
Friedrich I950: I5-I6; Riquer ı959: 27 п n.). Vegeu-ne ara les anàlisis més detallades de Badia I99I-92: 33-37, i Cingolani 2002: 222-24; 2006: 82-89 i nn.

34. Cf. Lo somni II,iv,9, ll. I82-84: "A mi plau -dix ell- ésser entès per tu, mas, si possible fos que no·m calgués en açò plus avant proçehir, bé·m fóra plasent, car, recordant mon defalliment, me renovella la tristor; però, pus axí ho vols, hojes" (Cingolani ed. 2006: I72-73); Inf. XXXIII, 4-9: "Poi cominciò: 'Tu vuo' ch'io rinovelli / disperato dolor che 'l cor mi preme / già pur pensando, pria ch’io ne favelli. // Ma se le mie parole esser dien seme / che frutti infamia al traditor ch'i’ rodo, / parlare e lagrimar vedrai insieme.” Per a l'íncipit del llibre tercer (“Axí com aquell qui, ab ardent desig, 
remarcable, però no pas concloent, amb la Vita nova. ${ }^{35}$ I, pel que fa a la menció de personatges presents en la Commedia, l'afinitat sembla textual en els casos d'Epicur i de Tamiris, no pas en el de Nemrod. ${ }^{36}$

Com hem vist a propòsit de Diògenes i el vell del Llibre de Fortuna e Prudència, el ressò d'un personatge dantesc, com ara Epicur o Tirèsies, sempre és susceptible d'involucrar la influència d'una glossa, i aquesta pista exegètica ha estat repetidament explorada a propòsit d'Orfeu, amb resultats diversos. Stefano M. Cingolani (I999: 265; 2002: 208-I5; 2006: 78-90) ha assenyalat una possible influència de les Esposizioni sopra la Commedia de Boccaccio en alguns detalls de la narració autobiogràfica d’Orfeu (Lo somni III,ii,3-5) que Martí de Riquer (1959: 26o n.) havia relacionat amb la Genealogia deorum gentilium. Una comparació sistemàtica dels tres textos (Gómez 2002: 84-85) potser no resol definitivament la qüestió (Cabré 2005-2006: 258 n. I3), però avui és segur que Metge va fer servir la Genealogia en aquest lloc i també en d'altres (Gómez 2002: 76-77; 2009-IO: 37-4O; Cabré 2005-2006: 254). D’altra banda, la possibilitat que Metge treballés alhora amb totes dues obres - l'una en llatí i l'altra en vulgar- no desdiu gens dels seus hàbits compositius. Per tant, convé de remarcar que l'anotació crítica de Cingolani (ed. 20o6) ha estès la possible influència de les Esposizioni - en combinació amb altres fonts- no solament a l'autobiografia, la descripció infernal i la teoria poètica d'Orfeu (III,ii-iv,3-I8), sinó també a les mencions de Sòcrates (I,v,29), Epicur (II,vi,I4) i Semíramis, Júlia i Lucrècia (IV,iv,6, I3 i 22); a la ficció de l'autoencàrrec (II,vi,I6) i a la censura de la gola dels homes dissoluts (IV,v,53-54) - un passatge que, a parer meu, també té molt a veure amb Innocenci III, De miseria humanae conditionis II, XVII - XVIII, I.

Provar que Metge disposava pels volts de 1398 d'un manuscrit de les Esposizioni sopra la Commedia (I373-75) aportaria una nova evidència de la immediatesa amb què era capaç d'accedir a les novetats bibliogràfiques més singulars. Actualment se'n conserven només quatre testimonis florentins medievals: un de final del segle XIV i tres del XV (Branca I958-9I: I, I9-2O; Padoan 1994 [I965]: 7I3-I5; Bellomo 2004a, I7 I-83, esp. I75-76; Malato-Mazzucchi 20II: 24I-49, esp. 245-46 [C. Calenda]). A més a més, un litigi entre els hereus de Boccaccio en va retardar la difusió. Així, Benvenuto da Imola, que freqüentà la lectura Dantis de Boccaccio, no pogué servir-se del text de les Esposizioni en el seu comentari (I379-83) (Bellomo 2004a, I42-62; Malato-Mazzucchi 2OII: 86-I2O [P. Pasquino]), mentre que Francesco da Buti, que explicà públicament la Commedia a Pisa a partir del I385 i enllestí el seu comentari el I394 (Bellomo 2004a, 246-59; Malato-Mazzucchi 2OII: I922I8 [F. Franceschini]), fou el primer d'una sèrie de comentaristes que es beneficiaren profundament de les Esposizioni malgrat l'exigüitat de la tradició. De moment, només en conec una notícia d'inventari fora de la península italiana, en la biblioteca de l'humanista croat Marko Marulić de Split (I45O-I524), dins la República de Venècia (Branca I958-9I: 2, 25).

La cúria papal d’Avinyó no era un lloc privilegiat per a la difusió de literatura en vulgar, tot i que la Commedia de Dante o les Esposizioni de Boccaccio haurien merescut de constituir una excepció, entre d'altres. Tant la solemnitat de la cúria com el perfil professional de les delegacions destacades

spera hoir cosa nova"; Cingolani ed. 2006: I83); cf. Purg. XIII, I45: "questa è a udir sí cosa nova”.

35. Cf. Lo somni III,vi,28, Il. 338-40: "Si és ta muller, follament has parlat, car has loat tu mateix, per tal com ella és carn de la tua carn e os dels teus ossos. E loar si mateix, si Aristòtil ha dit ver, és cosa fort vana"; Vita nova I9 [XXVIII], 2: "non è convenevole a me tractare di ciò, per quello che tractando, converrebbe essere me laudatore di me medesimo, la qual cosa è al postutto biasimevole a chi lo fa ...”" (Rossi ed. 1999: 154)

36. Per a Epicur, of. Lo somni II,vi,I4, Il. 325-26: "seguint la oppinió de Epicuri, havies per clar aquella morir qualque jorn ab lo cors", i 34I-42: "pusques induhir los sequaçes de la tua dampnada oppinió" (Cingolani ed. 2006: 178-79); Inf. X, I4-I5: "con Epicuro tutti i suoi seguaci, / che l'anima col corpo morta fanno"). Per a Tamiris, cf. Lo somni IV,iv,7, 11. 99-IO4, esp. IO4: "Sanch has sadejada e de sanch te sadollaràs" (Cingolani ed. 2006: 234); Purg. XII, 55-57, esp. 57: "Sangue sitisti, e io di sangue t’empio". Per a Nemrod, ff. Lo somni III,viii, 45, Il. 619-20; Purg. XII, 34-36. 
hi afavorien la circulació d'una alta cultura llatina, però l'admiració internacional per la producció humanística de Petrarca i de Boccaccio també suscitava interès per llur obra en vulgar. Pel que fa a Dante, ens consta almenys la presència a Avinyó de l'exemplar que Boccaccio trameté a Petrarca probablement entre l'estiu de I35 I i el maig de I353, juntament amb el carmen laudatorium "Ytalie iam certus honos" (Carm. V), identificat amb l'actual Vaticanus latinus 3 I99. ${ }^{37}$ I és evident que Dante era ben conegut dins el cercle d'amistats italianes de Petrarca, com ho posa de manifest la cèlebre Familiaris XXI, 25 (maig-juny de I359), adreçada a Boccaccio, en què Petrarca exposa públicament els seus judicis -i les seves reserves- sobre Dante.

La Commedia no consta en els catàlegs conservats del palau papal d’Avinyó. En un primer inventari de la biblioteca de Benet XIII a Peníscola (c. I420) se n'enregistra finalment un exemplar (no. 935: "Item Dant in vulgari ytalico"; Faucon I886-87: 2, I40), alhora que en un memoràndum de "Libri emendi pro domino nostro Papa" s'esmenta un Dante en traducció llatina -sens dubte, la traducció amb comentari que Giovanni Bertoldi da Serravalle havia enllestit durant el concili de Constança (I/I16-I7) - i el comentari de Benvenuto da Imola: "Dantes reductus de lingua florentina ad latinam. Lectura Magistri Benvenuti super eodem in latino" (Faucon I886-87: 2, I5I)..$^{8}$ La notícia testimonia un interès personal de Pero Martínez de Luna, que fins i tot podria ésser anterior al seu accés al papat. En tot cas, Benet XIII havia establert la seva residència habitual a Catalunya des de l'estiu de I409, després d'haver passat uns quants anys a la Ligúria (Savona, Gènova, Portovenere) -era el temps en què mestre Felip de Malla, bon coneixedor de la Commedia, predicava coram papam. Aquestes circumstàncies fan impossible de determinar tant l'origen com la data d'adquisició del manuscrit dantesc del papa Luna. ${ }^{39}$

A propòsit de l'entorn de Benet XIII, també convé de recordar una famosa carta que el dilluns 20 de febrer I408 el rei Martí escrigué des de Barcelona al governador general de Catalunya, Guerau Alemany de Cervelló, encarregat de gestionar prop del papa Luna, a Savona, la concessió de certes gràcies i butlles necessàries per a la fundació del convent dels celestins del Palau Major. No era la primera vegada que el rei hi insistia, i per això li demanava irònicament si, pel fet d'esperar-ne pacientment una resposta, havia de considerar-se tan il.lús com els qui consultaven la Sibil.la, segons Dante..$^{\circ}$ A més de constituir la primera menció explícita de l’autor de la Commedia a

37. Billanovich I947b: I45-48, I6I-75 i 234-40; Petrocchi I994 [I966-67]: I, 89-9г. Avui resulten de consulta ineludible Trovato-Tonelli-Bertelli-Fiorentini ed. 2013 (que posposen la dedicatòria fins al I359), i Piacentini 20 O $_{4}$.

38. Farinelli (I922: 2I 7) difongué la greu imprecisió de considerar totes tres obres en possessió de Benet XIII a Avinyó, tot i que Hamilton (ı9ог: 23-24 n. 22), al-legat com a font, havia reproduït amb exactitud les dades del catàleg. Els aclariments oportuns de Di Stefano (I974: I6I-62) tampoc no tenen prou en compte la llarga residència de Benet XIII a la Ligúria i a Catalunya. Val a dir que Hamilton es decantà finalment per identificar la traducció llatina del memoràndum amb la versió en hexàmetres de Matteo Ronto, avui datada posteriorment (I427-3I); vegeu Gómez 2OI6: I65.

39. No en queda rastre en els inventaris pòstums de I 423 (Perarnau I987), però cal tenir en compte que una part de la biblioteca de Peníscola degué passar a Gil Sanxis-Munyós i Carbon, papa Climent VIII. En els inventaris de la biblioteca que tenien a Terol els barons d'Escriche - mossèn Pero Sanxis-Munyós, cavaller, i Gaspar Joan SanxisMunyós- reapareix un Dante (Barcelona, Biblioteca de Catalunya, ms. 23I [I484], no. 3; ms. 234 [I530], no. IO5): “otro libro, en pergamino, intitullado el Dant, letra escolástica, cubiertas bermejas” (Wittlin r962: 6).

40. Cf. Par. XXXIII, 65-66: "così al vento ne le foglie levi / si perdea la sentenza di Sibilla”; Rubió i Lluch igo8-2r: I, 442-43, doc. 5o9: "e semble nts que aço sia la faula de Sibilla que Dant toque en lo seu libre, dient que com lo seu sepulcre fos en un gran bosc e molts vinguessen alli per haver responssions de lurs demandes, los quals scrivien ab letres d or en les fulles dels roures, e puys els se $\mathrm{n}$ anassen e a cap d algu temps tornassen alli matex per haver les dites respostes e trobassen les fulles dels dits roures perdudes, les unes per vent, les altres per sequedat, seguie s que, per gran treball que sostinguessen, no podien trobar ni haver les dites respostes. aquesta Sibilla excuse molt Dant dient que no era la culpa sua, mas dels homens qui per lur paguesa li fahien la dita interrogacio, perque nos volriem esser clar ab vos si es culpa vostra o peguesa nostra de demanarho." 
la Corona d'Aragó, l'evocació d'aquest símil dantesc s'embolcalla clarament de la seva exegesi: una paràfrasi moralitzada del rerefons virgilià (Aen. III, 44I-57, i esp. VI, 74-75), que esdevingué tradicional en la crítica dantesca. ${ }^{11}$ Tot i la manca de iussio ("Dominus rex misit eam signatam expediendam"), la carta no sembla atribuïble exclusivament al rei sense la intervenció d'algun dels seus secretaris d'aquests anys - Joan de Tudela o Bernat Metge. En tot cas, podem estar segurs que pels volts de I408 Dante era un auctor reconegut a la cancelleria i a la cort del rei Martí, llegit amb l’assistència de glosses i aprofitat com a repertori de símils i sentències.

\section{Trobadors, lírica francesa i Dante estilnovista}

Encar ncara al tombant de segle, i gairebé al mateix temps que en Lo somni de Bernat Metge (c. I398) es van collir les primícies d'una lectura dantesca que el ressò primerenc del Llibre de Fortuna e Prudència (I38I) certifica d'una precocitat excepcional, l'obra lírica d'Andreu Febrer, Gilabert de Pròixida i Melcior de Gualbes esdevenia l'altre fruit saborós d'una lectura de Dante que no es limitava pas a la Commedia..$^{42}$

El vigatà Andreu Febrer, nebot del jurista Jaume Callís, degué entrar de ben jove al servei de la Cancelleria Reial. En un document del 2 de març de 1390 encara consta a Vic simplement com a discretus i scriptor, però el 22 de novembre de 1392 ja fou creat notari públic per Joan I, amb referència explícita a la seva pertinença a l'escrivania del rei. A la mort del rei Joan, Febrer continuà vinculat a la reina Violant i a l'escrivania del rei Martí, però el 7 de març de I398 ja havia passat al servei del seu fill, Martí el Jove, rei de Sicília, com a cambrer, i el I4O7 s'encarregà de delicades missions diplomàtiques i de la persecució del rebel sicilià Artal d’Alagó a París. 43 Les quinze poesies que en conservem (Riquer ed. 195I) gràcies al cançoner Vega-Aguiló (c. I425) remunten sens dubte a aquest període de joventut, constitueixen probablement un cançoner dedicat a la reina Maria de Sicília (Cabré-Torró 20I5: I6I-64), i són el millor fruit d’un “trobador estudiós”, amb la sòlida formació retòrico-gramatical d'un escrivà de la cancelleria, però també amb una extraordinària familiaritat amb la tradició lírica pròpia, d'arrel trobadoresca, i amb les tradicions francesa i italiana (Cabré-Torró 20I5: 156-6I). Ja en plena maduresa, Andreu Febrer enllestia a Barcelona, l'i d'agost de I429, la seva traducció íntegra de la Commedia en decasílllabs catalans -la primera en vers en qualsevol llengua vulgar (Gallina ed. 1974-88).

La influència de la Commedia en l'expressió lírica d'Andreu Febrer ha estat confirmada repetidament per la crítica, ${ }^{44}$ si més no perquè en el Sirventesch per lo passatge de Barbaria (VIII) que Febrer va compondre entre el març i l'agost de $139^{8}$-abans de participar en la fallida croada punitiva del sacrilegi barbaresc de Torreblanca- s’hi percep un ressò força nítid del famós símil

4I. Vegeu Gómez 20i6: I62-65, i cf. Iacomo della Lana, ad locum: "la Sibilla, che fue al tempo di Eneas, volendo sue sentenze essere ascoste, le scrivea con lo licore d'alcune erbe su le foglie delli arberi, e questa scrittura durava tanto quanto la foglia stava verde; come la foglia cadea per vento, essa si seccava e diventava del colore della scrittura, sí che non si dicernea la scrittura in su la foglia, e cosí si perdea" (Volpi-Terzi ed. 20og: 2679), glossa represa quasi literalment per l'Ottimo commento (Torri ed. I829: 3, 73I); Chiose ambrosiane, ad locum: "Nam Sibilla scilicet Cumana solebat dare responsa in foliis scripta volantibus. Quod nichil aliud est dicere nisi quod responsa vaticinantium sunt ludibriosa et penitus aspernenda et deridenda" (Rossi ed. I990: 288).

42. Per als possibles ressons del Canzoniere de Petrarca en la poesia catalana d'aquest període, vegeu Espadaler 2OI5, i també Torró 2OI4: 286-88 (Andreu Febrer [amb Cabré-Torró 2OI5: I5O-6I]), 3OI-3O2 (Pere de Queralt), 303-3O5 (Melcior de Gualbes) i 307 (Llorenç Mallol).

43. Les síntesis biogràfiques més actualitzades són les de Torró 20I4: 279-8I, i Cabré-Torró 20I5: I53-56; vegeu també Riquer I95г: 5-26 і г29-І33, І70, і г967; Romano 1975-76; Parera 2006: 5-Iо.

44. Vegeu Milà i Fontanals I89o: 502; Montoliu 1923: 9I-98; Riquer I951: 54-57. 
virgilià (Aen. VI, 309-IO) d'Inferno III, II2-I4.45 A part d'això, la crítica recent ha coincidit a reconèixer en el cançoner d'Andreu Febrer una influència decisiva de les Rime de Dante i potser també de la Vita nova (Torró 2OI4: 28I-86; Cabré-Torró 2OI5: I57-60). L'artifici versificatori dels estramps (I i X) s'ha revelat una feliç innovació de Febrer, inspirada per l'ús del mot rima en Arnaut Daniel (Pujol r988-89) i en el Dante de les petrose (Siviero I997: I27-30; Di Girolamo-Siviero I999; Di Girolamo 2003: 53-57). La cançó en estramps "Sobre.l pus naut” (I) -una sublim visió al-legòrico-astrològica en lloança de la reina Maria de Sicília (I363 - 25 de maig de I4OI), primera muller de Martí el Jove-,${ }^{46}$ ha estat relacionada amb el registre poètic del Paradiso (Montoliu I923: 92-94) i de la cançó "Io son venuto al punto della rota" $(\mathrm{C})$, primera de les rime petrose (Torró 2OI4: 283; Cabré-Torró 20I5: I57). Hom ha reconegut la influència d'aquesta mateixa petrosa i també de la segona, "Al poco giorno ed al gran cerchio d'ombra" (CI), rere l'exordi hivernal de l'altra cançó en estramps "Combas e valhs" (X), ${ }^{47}$ també situable a Sicília (Torró 2014: 285; Cabré-Torró 20I5: I57-58). Finalment, els senyals "Beatriu” i “Àngel” de la lírica de Febrer podrien remetre al Dante de la Vita nova (Torró 20I4: 286; Cabré-Torró 20I5: I6o), tot i que Beatriu sembla també una

45. Cf. "Dolorós critz" (VIII), vv. 25-36: "Lavòs dirà que no pot mays compendre, / lo preyon potz del infernal abisme, / dels sperits qu·exiran del morisme, / car al intrar feran lo portal fendre, / e no·y haurà satans qui plus ne vulha, / ans diran tots: 'Gitatz-los los defora!'; / e li crusats crideran: ‘'Er és l'ora / que.l lach d'infern tots los moros aculha!' / / Si tombaran com fay la sequa fulha / dels cims dels branchs, que.l forts vent enderrocha, / barbres, e turchs, alarps e.ls de Marrocha, / e nós firén pendrem la lur despulha" (Riquer ed. 1951: 88; la cursiva és meva); Inf. III, II2-I4: “Come d'autunno si levan le foglie / l'una appresso de l'altra, fin che 'l ramo / vede a la terra tutte le sue spoglie ...". Aquest reflex, només qüestionat per Post (I9O8: 5I), ha estat reconegut i contextualitzat per Farinelli I9O2-I9O5; I922: 8I-82 i n. 2; Montoliu I923: 97-98; Riquer I951: IO-II i 55, i Parera 2OIO: I67 n. IO. Segons Torró (2OI4: 282), "Podria ser que Andreu Febrer ja combinés records de Dante i d’Arnaut Daniel, del qual són característiques les rimes fuelha / despuelha i versos com 'Ans que cim reston de branchas / sec ni despuelhat de fuelha”" (PC 29.3, vv. I-2).

46. Riquer I95: І33-36; I967: 428-29. L’àmplia datació de la cançó (г39O-I4OI) suggerida per Riquer (I95: I36) s'hauria de restringir als anys I398-I4OI en què Febrer consta adscrit al servei de Martí el Jove; altrament, hauria d'ésser anterior a la partença de Martí i Maria cap a Sicília després de llur casament a la darreria de I39I - una ocasió que hauria justificat el panegíric, però en la qual no consta encara cap vincle de Febrer amb la cort ni encara menys amb Maria; $c f$. Manual de novells ardits I, 23 de desembre de г39г: "Se recollí la Regina de Sicilia en I galea entrant en aquella per un pont de fust que la ciutat li feu prop la torra de Sent Nicholau a la mar. E foli feta festa y aportat I pali ...”; I7 de febrer de I392: "Partí lo senyor Duch ab son benaventurat estol del port de Calalobera [...] per fer son bon viatge vers lo regne de Sicilia ab linfant Don Marti fill seu e ab lalta Regina de Sicilia muller del prop dit Infant ...” (Schwartz-Carreras ed. I892: 23 i 26). A falta d'una cerimònia solemne de coronació, ignorem quina ocasió concreta pogué motivar aquesta exaltació retòrica de la reina. Després d'una gravíssima malaltia, el I398 coincideix amb el seu embaràs i el naixement de l'hereu Pere (I 7 de novembre), batejat el dia de Sant Jordi de I399 i mort en tràgic accident el 8 de novembre de I4OO (Lo Forte Scirpo 2003: 9I-I22); aquest fet luctuós i la malaltia subsegüent permeten de restringir encara més la datació (I398-I400). La cançó no al-ludeix explícitament a la maternitat de la reina, però potser ho fa implícitament amb la seva assimilació a la Mare de Déu (Torró 20r4: 283). Amb l’ús del senyal “Loyndan·amor” (v. 69) el poeta sembla ubicar-se a Sicília (Torró 2OI4: 265 i 284), mentre que la fama que augura a la reina "si.ls amichs de Mahoma / ffayts abaxar de lur malvada secta" (vv. 67-68; Riquer ed. г95г: 63) podria referir-se a la croada punitiva de l'agost de r398 o a la del setembre de 1399 (Lo Forte Scirpo 2003: ІІ3). Malauradament, no podem confirmar si la factura artificiosa del panegíric pot tenir a veure amb una possible participació del poeta en algun dels certàmens del Consistori de la Gaia Ciència de Barcelona, celebrats el dia de Pentecosta (com ara el 26 de maig de I398) d'ençà de la seva refundació amb privilegi emès pel rei Martí des de Saragossa l’ı de maig de I398 (Rubió i Balaguer I984-88 [I948-59]: I, 2OO-203; Riquer I984 [I964]: 2 , 68-69; Casas Homs ed. 1956: 2, 444-46). La tornada de la cançó "Le sovenirs" (VI) de Gilabert de Pròixida (vv. 4I-42: "Dona ses par: ab amorosa cura / offir mon xant al novell cocistori ...”) permeté a Riquer (i954: 8) de relacionar-la amb la primera fundació del Consistori per Joan I (I393), i potser no és casual l’ús del mot "cossistori” com a rim estramp (v. 47) en la cançó de Febrer, ni tampoc la imitació que en féu un poeta de certamen com Llorenç Mallol en la cançó "Sobre.l pus alt de tots los cims d'un arbre" (Torró 20I4: 3o6-3O7; $c f$. vv. 45-48: "O vers, si·t plazt, vayte n’al consistori / del Gay Sauber, qui·s nomne per lo mon, / e en sopleyan al senyor set qui y son / que·t vullyen dar esmenda y adiutori”). Sobre l’èxit del panegíric de Febrer, vegeu Cabré-Torró 20I5: I62.

47. Vegeu els arguments de Di Girolamo 2003: 56; Grifoll 2006; Cabré 2007. 
revelació del nom real de la seva dama (Riquer 1951: 54-55).

Una diferent assimilació de les mateixes tradicions trobadoresca, francesa i italiana caracteritza la dicció emotiva i delicada del cavaller valencià Gilabert de Pròixida (Riquer ed. I954), documentat entre I388 i I40I com a talladorer i coper del rei Joan i com a cambrer del rei Martí. El I392 desembarcà a Sicília i entrà a Palerm, i el I394 hi tornà amb Pere Maça aportant reforços al setge de Catània. Implicat des del I396 amb els Centelles en les bandositats valencianes contra els Vilaragut, finalment es degué veure obligat a enrolar-se en una armada de suport a Benet XIII i morí de pesta a Gènova l'octubre de $\mathrm{I} 4 \mathrm{O} 5 \cdot{ }^{{ }^{\circ}} \mathrm{La}$ crítica ha reconegut una possible empremta de la Vita nova en dues de les seves composicions. En la cançó “Dona del món” (X), Riquer (1954: 22-23) hi assenyalà amb molta cautela un possible reflex del motiu de la donna schermo ( $\left.V N_{2}[\mathrm{~V}-\mathrm{VI}]\right)$, avui reforçat per Torró (20I4: 292-94) amb el motiu de la lloança purificadora ( $V N$ IO [XVIII]); en la cançó laiada "Amant languesch" (XIII) semblen coincidir-hi motius i expressions de la introducció i dels versos del sonet celebèrrim "Tanto gentile" ( $\left.V N_{\mathrm{I}}[\mathrm{XXVI}]\right) .{ }^{49}$

Dos ressons més d'aquest sonet són clarament perceptibles en les cançons "Pus me suy mes" i "Palays d'onor" de Melcior de Gualbes, ${ }^{50}$ de qui només conservem quatre composicions, totes sembrades d'estilemes de Petrarca i de la tradició estilnovista (Riquer 1954-56; Alberni 2002; Torró 20I4: 303-305). L'estilema emblemàtic cor gentil es repeteix en la cançó "Pus me suy mes" i en un cobla esparsa que expressa l'enyor evocant la cançó "La dispietata mente che pur mira" (L) de Dante..$^{{ }^{\mathrm{r}}} \mathrm{El}$ ciutadà i patró de naus barceloní Melcior de Gualbes, germà de l'eminent jurista Bernat de Gualbes, que estudià a Bolonya, era talladorer de Joan I el I395, any en què consta interceptant naus genoveses -Gènova afavoria llavors les pretensions de Giangaleazzo Visconti de Milà al tron de Sicília, en connivència amb els rebels sicilians Artal d'Alagó i Enrico Chiaramonte (Lo Forte Scirpo 2OO3: 87-9I) -, i era cavaller el I4I2, però morí abans del desembre de I4I5 (Torró 2OI4: 3O2-303).

Gilabert de Pròixida, Andreu Febrer i Melcior de Gualbes entraren al servei de la cort durant el regnat de Joan I, participaren en els projectes d'expansió mediterrània de la monarquia, coordinats per Martí, i, a recer d'un poder que promovia la revitalització de la tradició trobadoresca, impulsant el Consistori de la Gaia Ciència de Barcelona (I393-96, I398) i la imitació de poetes francesos com Guillaume de Machaut i Oton de Grandson (Pagès I936; Alberni 2Oıо i 2OI2; Marfany 2OI2; Zinelli 2OI2), també assimilaren la veu del Petrarca volgare i, sobretot, la de Dante: no solament, però, el de la Commedia, sinó també el Dante estilnovista de la Vita nova -amb l'èxit esclatant del sonet "Tanto gentile”- i d'una breu sèrie de canzoni, com ara la L o les petrose Ci CI. Jaume Torró (2OI4: 264) identifica aquest Dante amb precisió:

Dante degué arribar en la forma de llibre que es coneix com la vulgata o silloge boccaccesca,

48. Per a la biografia, vegeu especialment Alberni 2005; Riera i Sans 2008, i Torró 20I4: 29O-9I.

49. Vegeu Molas i955; Riquer I984 [I964]: 2, 80-8I, i Torró 20I4: 294. Cf. “Amant languesch” (XIII), vv. 3I-32: “¡A, dona proz, de valor coronada, / que.us faytz pel món a totes gens lausar!” (Riquer ed. 1954: 69); VN I7 [XXVI], 2: "Ella coronata e vestita d'umilitade s'andava”, i 6 [“Tanto gentile”, vv. 5-6]: "Ella si va, sentendosi laudare, / benignamente d'umiltà vestuta" (Rossi ed. 1999: I4I i i 43 ).

50. Cf. "Pus me suy mes", vv. 37-38: "totz le mons veu qu'es flor d'onor mundana, / plena d'umil e benigna manera" (Riquer ed. I954-56: I7I); "Palays d'onor", vv. 43-44: "celhs qui us ven van disen de grans tretz: / de paradis nos semble que devalh" (Alberni ed. 2002: I6I); $f$. Dante, $V N_{\text {I }}$ [XXVI], 6 [“Tanto gentile”, vv. 7-8]: "e par che sia una cosa venuta / da cielo in terra a miracol mostrare" (Rossi ed. I999: I43).

5. Cf. "Acompanyat", vv. I-3: "Acompanyat d’un amorós desir / qui·m ve de vos, belha, per luny que sia, / m'esforç totz jorns membrar e sovenir”, i v. 7: “de cor gentil” (Riquer ed. 1954-56: I75); Rime, L, vv. 4-5: "e ’l disio amoroso che mi tira / verso 'l dolce paese c'ho lasciato" (De Robertis ed. 2005: I59). Per a desig en l'accepció de "nostàlgia', un patró de naus com Melcior de Gualbes hauria apreciat especialment l'exordi de Purg. VIII, I-3: "Era già l'ora che volge il disio / ai navicanti e 'ntenerisce il core / lo dì c'han detto ai dolci amici addio ..." 
composta per la Comèdia, la Vita nova i cap a una quinzena de cançons, entre les quals hi havia les Rime petrose. Si Andreu Febrer s'interessà més pel Dante aspro, que enllaçava amb Raimbaut d'Aurenga i Arnaut Daniel, Melcior de Gualbes ho féu pel Dante dolce, que connectava amb Giraut de Bornelh.

La tria i la seqüència de cançons d'aquesta silloge (CIII, LXXIX, LXXXI, LXXXII, XC, XCI,

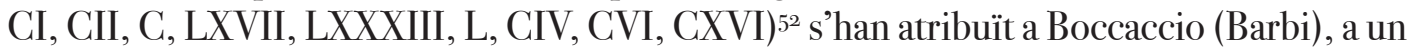
compilador precedent (De Robertis) o, fins i tot, a Dante, atès que aquest Libro delle canzoni podria correspondre al programa original, inacabat i reformulat, del Convivio. ${ }^{33}$ Sigui com vulgui, Boccaccio fou determinant en la difusió extraordinària d'aquesta sèrie, copiada en tres dels seus autògrafs entre la dècada dels 50 i el I366: el Toledano IO4 6 (Trattatello [Ia red.] de Boccaccio, Vita nova, Commedia amb els tres Argomenti en terza rima de Boccaccio i Libro delle canzoni), el Riccardiano IO35 (Commedia amb els Argomenti i Libro delle canzoni) i, finalment, la secció dantesca -més antiga- del Chigiano L V I76 (Trattatello [2a red.], Vita nova, carmen "Ytalie iam certus honos" de Boccaccio [2a red.] i Libro delle canzoni), que constituïa una unitat amb el Chigiano L VI 2I3 (Commedia amb els tres Argomenti). 54

Aquest Libro delle canzoni, amb les quatre petrose C-CIII, i la Vita nova, amb el sonet "Tanto gentile", exerciren una influència segura en els trobadors catalans del tombant de segle, segurament a partir d'una tradició manuscrita derivada de Boccaccio que també podia incloure el Trattatello in Laude di Dante, a més de la Commedia amb els tres Argomenti (o Brieve raccoglimento). La data i les vies d'arribada d'aquest corpus són incertes, però podrien remuntar-se al regnat de Joan I i a les primeres vicissituds de la conquesta martiniana de Sicília -sense excloure altres possibilitats, com ara Gènova o Bolonya.

\section{Una connexió siciliana ( $\left.1367_{7-1} 4 \mathrm{I} 3\right)$}

En la primera redacció de la seva Vita di Dante o Trattatello in laude di Dante (c. I35/55), Giovanni Boccaccio recull dues tradicions contradictòries a propòsit dels possibles dedicataris de la Commedia: "secondo il ragionare d'alcuno" (§ I93), Dante volgué dedicar l'Inferno a Uguccione della Faggiuola, senyor de Pisa des de final de I3ı3; el Purgatorio a Moroello Malaspina, marquès

52. Vet aquí els íncipits segons l'ed. De Robertis 2005 [2002], però amb la numeració romana canònica de l'ed. Barbi de I92I: "Così nel mio parlar vogli'esser aspro" (CIII [г]), "Voi che 'ntendendo il terzo ciel movete" (LXXIX [2] = $C v$. II), “Amor che nella mente mi ragiona" $(\mathrm{LXXXI}[3]=C v$. III), "Le dolci rime d'amor ch”io solea" $(\mathrm{LXXXII}[4]=C v$. IV), "Amor che movi tua vertù dal cielo" (XC [5]), "Io sento sì d’Amor la gran possanza” (XCI [6]), "Al poco giorno ed al gran cerchio d'ombra" (CI [7]), "Amor, tu vedi ben che questa donna" (XCII [8]), "Io son venuto al punto della rota" (C [9]), "E’ m’incresce di me sì duramente” (LXVII [Io]), "Poscia ch’Amor del tutto m’ha lasciato" (LXXXIII [II]), “La dispietata mente che pur mira" (L [I2]), “Tre donne intorno al cor mi son venute” (CIV [I3]), “Doglia mi reca nello core ardire” (CVI [14]), “Amor, da che convien pur ch’io mi doglia” (CXVI [I5]).

53. Noteu que LXXIX, LXXXI i LXXXII són les cançons comentades en els tractats II, III i IV del Convivio, i que Dante declara la intenció de comentar "Tre donne intorno al cor mi son venute" (CIV) en el tractat XIV (Cv. I, XII, I2) i una cançó identificable amb "Doglia mi reca nello core ardire" (CVI) en el darrer tractat (Cv. I, VIII, I7-I8). "Così nel mio parlar vogli’esser aspro” (CIII) s’hauria pogut desplaçar al capdavant com a definició d’una poètica. Vegeu Leonardi 2004; Tonelli 2006; Tanturli 20I3, i la revisió de Grimaldi 20I4, que recupera el punt de vista de Michele Barbi.

54. El Libro delle canzoni es recull en dos manuscrits quantrecentistes de la Biblioteca Nacional de Madrid procedents de la biblioteca del Marquès de Santillana: el ms. IO258 conté el Convivio, el Libro delle canzoni i tres cançons de la Vita nova: "Donne ch'avete intellecto d'amore" (Io [XVII]), "Donna pietosa e di novella etate" (I4 [XXIII]) i "Gli occhi dolenti per pietà del core" (20 [XXXI]) (Schiff I9O5: 273-74); el ms. IO227 conté el Trattatello de Boccaccio i el Libro delle canzoni, seguits de tres orationes de Stefano Porcari i una traducció italiana del De senectute de Ciceró (Schiff r9o5: 329-3i). 
de Lunigiana, mort el 8 d'abril de I3I5, 55 i el Paradiso a Frederic d’Aragó, rei de Sicília (I296-I337); d'altres, en canvi, afirmen (§ I94) que Dante dedicà tota la Commedia a Cangrande della Scala:

Questo libro della Comedia, secondo il ragionare d'alcuno, intitolò egli a tre solennissimi uomini italiani, secondo la sua triplice divisione, a ciascuno la sua, in questa guisa: la prima parte, cioè lo 'Nferno, intitolò a Uguiccione della Faggiuola, il quale allora in Toscana signore di Pisa era, mirabilmente glorioso; la seconda parte, cioè il Purgatoro, intitolò al marchese Moruello Malespina; la terza parte, cioè il Paradiso, a Federigo III re di Cicilia. Alcuni vogliono dire lui averlo intitolato tutto a messer Cane della Scala; ma, quale si sia di queste due la verità, niuna cosa altra n’abbiamo che solamente il volontario ragionare di diversi; né egli è sì gran fatto che solenne investigazione ne bisogni. (Trattatello, ra red., §§ 193-94; Sasso ed. 1995: 72)

Boccaccio s’abstingué en aquesta ocasió de triar entre les dues opcions, però en la segona redacció del Trattatello (c. I364/66; $\$ \S ~ I 3{ }^{\mathrm{I}}{ }^{2}{ }^{2}$ ) es decantà a favor de la segona ${ }^{56} \mathrm{i}$, finalment, en l'“accessus" de les Esposizioni (I373-75; § 74-77) s'estimà més d'obviar la qüestió. El principal fonament de la segona opinió era, òbviament, l'Epistola a Cangrande, tot i que la seva part dedicatòria (III, § II) es refereix exclusivament al Paradiso. El fonament de la primera es reduïa, d'altra banda, a un text d'autenticitat tan controvertida com l'“Epistola di frate Ilaro", que Boccaccio transcrigué a Nàpols cap a I340 -0, a tot tardar, a Florència el I342- en el seu Zibaldone Laurenziano. ${ }^{57}$ Satisfent un encàrrec personal del mateix Dante, fra Ilaro s'adreça a Uguccione della Faggiuola per oferir-li una còpia glossada de l'Inferno, alhora que el remet a Moroello i a Frederic si mai voldrà obtenir les altres dues parts:

[20] Si vero de aliis duabus partibus huius operis aliquando mangnificentia vestra perquireret, velud qui ex collectione partium ad integrare proponit, ab egregio viro domino Morello marchione secundam partem que ad istam sequitur requiratis; et apud illustrissumum Fredericum Regem Cicilie poterit ultima inveniri. [2I] Nam sicut ille qui auctor est michi asseruit se in suo proposito destinasse postquam totam consideravit Ytaliam, vos tres omnibus preelegit ad oblat[i]onem istius operis tripartiti. (Arduini-Wayne Storey ed. 2006: 86)

Fos quina fos la intenció de Dante pels volts de I3I4, és ben segur que no fou pas a Frederic III de Sicília, sinó, en tot cas, al vicari imperial Cangrande della Scala, senyor de Verona, que dedicà els primers cants del Paradiso. Fins i tot és improbable que Frederic arribés mai a conèixer la Commedia, tot i que el seu compromís polític amb el gibel-linisme, i l'acolliment que dispensava als partidaris d'una reforma radical de l'Església i als franciscans espirituals, no permeten d'excloure

55. Convé de recordar que el I3o6 Moroello Malaspina dispensà protecció a Dante, el qual li dedicà, poc després d'acomiadar-se'n (I3O7-I308), l'Epistola IV amb la cançó montanina “Amor, da che convien pur ch'io mi doglia" (Rime CXVI).

56. Cf. Trattatello, 2a red., § I32: "Alcuni voglion dire lui averlo intitolato tutto a messer Can della Scala; e io il credo più tosto, per la maniera che tenne di mandar prima a lui quello che composto avea che ad alcuno altro" (Sasso ed. I995: II6). Sobre aquesta relació amb Cangrande, vegeu Trattatello, ra red., § I83; 2a red., § I22.

57. Giorgio Padoan (1971; 1993: 5-23) defensà amb fermesa l'autenticitat de l'epístola, datant l'entrevista entre Dante i Ilaro cap a I3I4/I5, període en què - enllestit ja l'Inferno, potser encara no el Purgatorio- Uguccione i Moroello, vicaris imperials, i Frederic III de Sicília, almirall de l’Imperi, prometien de continuar l'obra política del difunt Enric VII. Tanmateix, els arguments de Padoan no han aconseguit de dissipar l'escepticisme de la crítica, molt consolidat després que Giuseppe Billanovich (I947a) considerà l'epístola una mena d'exercici retòric realitzat pel mateix Boccaccio a partir de textos dantescos. Recentment han reprès la discussió Saverio Bellomo (2004b) -que l'atribueix a Giovanni del Virgilio-, Giuseppe Indizio (2006a i 20o6b) -que la considera autèntica i probablement facilitada a Boccaccio per Sennuccio del Bene- i Alberto Casadei (2OII) - que la considera parcialment autèntica, però manipulada. 
cap possibilitat. Cal no oblidar fins a quin punt Dante havia enaltit la virtut del seu pare i la del seu germà, els reis d'Aragó Pere el Gran i Alfons el Franc o el Liberal, malgrat les crítiques infligides a Jaume II d'Aragó i al mateix Frederic:

Quel che par sì membruto e che s'accorda, cantando, con colui dal maschio naso,

d'ogne valor portò cinta la corda;

e se re dopo lui fosse rimaso

lo giovanetto che retro a lui siede,

ben andava il valor di vaso in vaso,

che non si puote dir de l'altre rede;

Iacomo e Federigo hanno i reami;

del retaggio miglior nessun possiede. (Purg. VII, II2-2O)

Per una via o per una altra, la Commedia arribà a la cort de Sicília a mitjan segle: el rei Frederic IV el Simple o el Senzill (1355-77), nét de Frederic III, posseïa el I367 "librum unum, dictum lu Danti, quod dicitur De Inferno", ${ }^{8} \mathrm{i}$ aquesta n’és la primera notícia segura. L'inventari pòstum (I377) de la biblioteca del franciscà llombard Matteo della Porta o de Cumis (Como), arquebisbe de Palerm (I366-77), també testimonia un exemplar de l'Inferno: "liber de Dantis in papiro qui incipit $\mathrm{Nel}$ mezo camin di nostra vita et finit Et quindi simu a vidir li stilli” (Monfrin 196r: 229; Williman 1980: 264 no. 98).

Frederic IV, educat probablement per fra Ubertino da Corleone, incorporà a la seva cort nombrosos franciscans com a pedagogs, capellans, diplomàtics i consellers (Rotolo I96I, I984 i 2007). Els primers testimoniatges de la influència de Dante en la cultura siciliana són, precisament, obres d'autors franciscans. El primer document que podem adduir és el Quadragesimale scolarum de Ruggero da Eraclea (Gela) -o, menys probablement, de Ruggero da Piazza-, que conté

58. Bresc 197I: I25 doc. 23; per a l’inventari complet dels béns reclamats pel rei al seu tresorer Niccolò de Reggio, vegeu Natoli I893: I4-I5 n. 3. Per a notícies de testimonis de la Commedia a la Sicília dels segles XIV i XV, vegeu Bresc I97I: 55-56, i Resta I967: 4I 4-I5, que subratlla el probable origen centroseptentrional dels testimonis i la inexistència d'una tradició textual siciliana; s'hi oposa Correnti r979: 58-63. En concret, consta una quinzena d'exemplars d'obres dantesques en Bresc i97ı: doc. 23 [rei Frederic III (Messina, I367)], Inferno; doc. 49 [mestre Robertus de Stephano (Palerm, I42I)], no. 26: "duo [sc. quaterni] de scripto Dantis"; doc. 65 ["magnificus dominus" anònim (Palerm, I432)], no. 2: "Item legavit conventui Sancti Francisci de Panormo librum unum vocatum lu Danti in pergameno cum aliquibus glosis quem dixit esse penes Dominum Franciscum Botzu arcium et medicine doctorem ex causa accomodate in terra Castrijohannis"]; doc. 77 [Baldassar de Afflicto (Palerm, I44I)], no. 5: "Item librum Dantis cum cohoperta rubea de tabulis in carta bonbicis", i Io: "Item librum Dantis de pergameno quem olim habebat Dominus Antonius de Vintimilio"; doc. IO2 [notari Stefano de Avillino (Messina, I449)], no. I8: "Item librum Dantis cum comento et tabula"; doc. Io6A [Leonardus de Bartholomeo, protonotari del regne (Palerm, I45O)], no. 59: "Item Danti in carta membrana"; doc. II7 [Jacobus Ispalensis, doctor en arts i medicina (Tràpani, I454)], no. 26: "Item unu libru chamatu Danti”; doc. I32 [cavaller Johannes de Abbatellis, "magister secretus" del regne (Palerm, I459)], no. Io: "Item liber Dantis pulcher in carta membrana"; doc. 134 [Thomasius Crispus (Palerm, I460), no. 3: "Item certa pars Dantis", i 7: "Item liber Dantis in carta membrana"]; doc. 194 [Jacobus de Chirco, doctor "utriusque iuris" (Palerm, I484)], no. 92: "Item librum Dantis vetus in carta bonbicis", i Io6: "Item alium librum Dantis veterem in carta bonbicis”; doc. I95A [noble Mattheus de Campo (Palerm, I487 [m. I484])], no. ı: "Item librum unum Domini Dantis in carta membrana”; doc. I96 [Leonardus de Minardo, doctor en arts i medicina (Palerm, I484)], no. I3: "Item Dantes in bona carta extimatus". A part d'una Commedia amb glosses (doc. 65, 2) i d'una altra amb comentari (doc. IO2, I8), a final del XV consten dos exemplars del comentari de Benvenuto da Imola (doc. I96 [I484], no. I2; doc. 207 [I487], no. 23). Per als fragments conservats, potser de la segona meitat del XIV, vegeu Gaudioso I93 (bocins de Paradiso XXV-XXVI i XXX-XXXI amb glosses interlineals i sobretot marginals, que en alguns casos són l'única part visible), i Giuffrida I969 i Giunta-Giuffrida-Sparti I983 (Inf. XI, 98-II5; XII, I-7, I6-45, 52-82 i 89-II8; XXI, 64-79; XXII, 32-47; XXX, I9-54, 57-91, 94-I48; XXXI, I-I3; Purg. IV, II-I35; V, I-I5). Per a la fortuna de Dante a Sicília, vegeu també Santangelo I976 [I985: I3-34], i Spalanca I998. 
nombroses citacions de la Commedia tant en una hipotètica primera redacció (I367-68) com en una altra, no gaire posterior, que en un testimoni s'acompanya d'un suplement de dotze sermons d'estil semblant i amb algun altre ressò dantesc. ${ }^{59}$ Els sermons del Quadragesimale, encara inèdit, rics d'exempla contemporanis, històrics i mitològics, contenen citacions de Dante, el "poeta vulgaris”, a propòsit dels temes següents: ${ }^{60}$

I. Sobre la mort espiritual del pecat (f. $\left.46^{v}\right)$ : Inf. I, II5-I7.

2. Sobre l'avarícia (f. $53^{\mathrm{r}}$ ): Inf. VII, 6I-66.

3. Sobre el servei a Déu o al món, l'exemple de Romeu de Vilanova (f. 59 `): Par. VI, I 4O-42.

4. Sobre el raptus de sant Pau (f. 62 ): Par. I, 73-75.

5. Sobre la imitació, l'exemple de Belisari (f. 62v): Par. VI, $25-28$.

6. Sobre l'enveja, l'exemple de Pier delle Vigne (f. 68r): Inf. XIII, 58-6o i $64-69$.

7. Sobre l'escola dels poetes i els dos cims del Parnàs, ço és el de Bacus, "deus scientiae”, i el d'Apol-lo, “deus sapientiae” (ff. 69 $9^{\mathrm{v}}-7 \mathrm{O}^{\mathrm{r}}$ ): Par. I, I3-I8 (“Unde poeta vulgaris tractavit de poesis Inferni et Purgatorii sub dictu Bachi, quasi dicat quod ratio naturalis seu moralis potest illa dictare quia ulterius tractaturus erat de Paradiso ubi sunt illa quae ratio naturalis nescit dictare, hinc est quod ipse dicit: ...” [cit. G. Palumbo 1967: 472]).

8. Sobre la supèrbia (f. $77^{r}$ ): Purg. XI, 9I-93.

9. Sobre la salvació (f. $\left.78^{v}\right)$ : Purg. XXI, I-3.

Io. Sobre la dolçor de la gràcia i la contemplació (f. 95v): Par. I, 7-9.

II. Sobre l'edat de Crist redemptor (f. IIO $\left.{ }^{\mathrm{v}}-\mathrm{III} \mathrm{I}^{\mathrm{r}}\right)$ : Inf. I, I-3.

I2. Sobre la segona mort de la damnació (137'): Inf. I, II5-I7.

La majoria de les citacions s'inclouen en la narració d'un exemplum de Dante o en un breu marc exegètic coherent amb la tradició crítica, al costat d'altres recursos promoguts pels classicizing friars: figures, mitografia, història, etc. És clar que es tracta d'un recull concebut per a ús de

59. Vegeu G. Palumbo I967; Roccaro r987 i r992; Cenci 1995; Romano 2008. Per a la datació, Cenci r995: 272-75. L'obra recull 56 sermons quaresmals (un per a cada fèria i dos per a cada diumenge) i figura l'Església com una Escola de Crist: després del tema, cada sermó enumera tres escoles il-lustratives; a continuació, una virtut o un vici, i es pregunta unde originetur, quomodo exercitetur i in quo figuretur. Se'n conserven sis testimonis (Cenci 1995: 279-90). Els dos testimonis de la hipotètica primera redacció $(L M)$ són mutilats i incomplets, però transmeten l'epístola dedicatòria de Ruggero da Eraclea al confrare sicilià Andrea da Alcamo, que també era present en un testimoni perdut $(G)$; els altres quatre testimonis són complets, però amb moltes variants: $B$ sembla còpia de $N$, adaptat a un públic de Nuremberg; $F$ i $A$ són copiats probablement a Florència i a Nàpols, i $A$ conté dotze sermons més, que Roccaro considera del mateix autor. L'atribució del quaresmal en $A$ és: “Incipit Quadragesimale editum a magistro Rogerio de Scicilia feria quarta cineris existente bachallario Neapoli [...] Ad usum fratris Stephani de Atella, provincie Apulie”, i només $F$ apunta una altra atribució, potser per confusió: "Istud Quadragesimale composuit Magister Rogerius de Placea ordinis Minorum provincie Scicilie”. Ruggero da Eraclea consta com a batxiller sentenciari en una butlla d’Urbà V (I3 de setembre de I367) en què ordena a mestre Ubertino da Corleone que el promogui al magisteri després d'examinar-ne la idoneïtat, juntament amb quatre mestres més, a l'estudi general de Bolonya o en un altre estudi general franciscà (Roccaro i992: 28-29; Cenci I995: 275-77 i 294 [text de la butlla]). Cenci suposa que per això el I368 degué acudir a San Lorenzo de Nàpols (ms. A) i predicar el Quadragesimale. No és pas segur que es pugui identificar amb un "Rogerius de Ceva de Heraclia”, capellà reial, que l’ı de gener de i376 és nomenat per Frederic IV capellà major de la capella reial de Palerm (Roccaro 1992: 30). Mestre Ruggero da Piazza (XIV ${ }^{\mathrm{in}}$-I383), fou bisbe de Bosa (Sardenya) transferit a la diòcesi de Mazzara el ı9 d'abril de ı363, capellà del jove rei Frederic des del ı367. No sabem si podem identificar amb l'un o amb

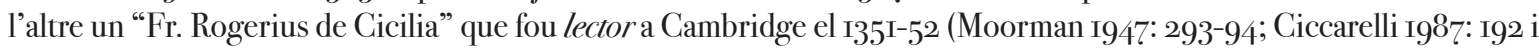
n. 80; Roccaro 1992: 28).

6o. Vegeu Palumbo 1967, a partir de $A$. Segons la descripció de Cenci, els testimonis mutilats contenen les referències $3(L M)$ i $6(L$, def. $M)$; els testimonis alemanys $N B$ només en conserven dues: In i ı2; sembla que $F$ transmet les citacions 2-6 i II-I2. Per als altres dotze sermons del testimoni $A$, vegeu Roccaro ed. r992; el primer sermó descriu la compareixença de justos i pecadors al Judici final, manllevant personatges de la Commedia (Roccaro ed. 1992: 7 I-72). 
predicadors, però alguns temes i la tria d'exemples (Pier delle Vigne, Romeu de Vilanova, el comte Belisari) fan pensar en una possible aplicació àulica, en relació amb la cort reial.

Un segon testimoni de lectura dantesca és la Sposizione del Vangelo della Passione secondo Matteo (I373), obra molt rellevant de la literatura siciliana del segle XIV, escrita per un bisbe franciscà anònim, amb calcs evidents de versos de totes tres cantiche de la Commedia (P. Palumbo ed. 1954-57). L'anònim, que es declara autor de tractats teològics en llatí (De futura vita, De domino Iesu Cristo ad infideles) i en vulgar (De Deo, De anima, Perki Deu factu fu homu), ha estat identificat amb Niccolò Casucchi di Agrigento (Palumbo I954-57: I, XIV-XXVI), amb l'arquebisbe Matteo della Porta (Monfrin I96I), amb Ubertino da Corleone (Rotolo r984) i amb Ruggero da Piazza (Resta I967: 4I9 i n. 29). ${ }^{\text {ri }}$

Dante, és clar, també devia ésser conegut en altres contextos socioculturals, especialment a la cancelleria siciliana. ${ }^{62}$ El I37 I Boccaccio escrivia des de Nàpols al cavaller messinès Giacomo o Iacopo Pizzinga, protonotari de Frederic IV ("celeberrimi nominis militi Jacopo Pizinge serenissimi principis Federici Trinacrie regis logothete”), una carta en la qual es dóna per descomptada la seva familiaritat amb Dante (Ep. XIX; Auzzas ed. 1992: 658-73 i 823-27). Boccaccio no coneix Pizzinga personalment, però ha tingut ocasió d'entrevistar-se amb fra Ubertino da Corleone -representant de Frederic IV davant la reina Joana en les negociacions del futur tractat de pau de I372-, que n’ha lloat l'enginy, la devoció per la cultura clàssica i l'ambició d'emular els poetes antics; una ambició que Boccaccio encoratja i que el faria mereixedor de la coronació poètica després de Dante, Petrarca i Zanobi da Strada. ${ }^{63}$ Malauradament, l’única mostra que conservem de la creativitat de Pizzinga és el carmen "Solve artus, attolle caput, tua brachia solve" o Versus in vituperium Sicilie (Sottili 1975: 302I4): una paròdia puntual de la laus Italie "Salve, cara deo, tellus sanctissima, salve" (Epist. III, 24 Ad Italiam) de Petrarca (Fera 2005).

No hi ha dubte que Dante i la seva Commedia eren ben coneguts a la cort de Frederic IV, i podem suposar que també ho eren a l'entorn dels quatre vicaris Alagó, Ventimiglia, Chiaramonte i Peralta. Per exemple, el franciscà Andrea de Pace da Sciacca, estretament vinculat a la cort siciliana del duc

6г. Sobre la qüestió, vegeu Ciccarelli г987: г9I n. 75; 2003: 2I n. 28; 2007: г34 n. 38; Roccaro I987: 275-76 n. IO; I992: I5-I6 ก. 9 .

62. És possible que el cronista Niccolò Speciale, contemporani de Ramon Muntaner, ja conegués l'Inferno (Labate I900; Resta I967: $4 \mathrm{I} 7$ i n. 24), mentre que els cronistes sicilians del segle XV citen Dante explícitament, sobretot a propòsit de la menció de Pere el Gran i la seva descendència en Purg. VII, II2-I2O (Resta I967: 42O-2I i nn. 32-33), com també fan, en català, Pere Tomic el I 438 i l'autor anònim de la novel·la Curial e Güelfa a mitjan segle Xv (Gómez 2OI4: $37^{-} 3^{8} \mathrm{nn}$. г26 i I27).

63. Vegeu Rotolo 1984: 729-30; 2007: 885; Ciccarelli 2003: 2I n. 28; 2007: I34 n. 38, i sobretot De Stefano I957, que documenta l'activitat política i administrativa del cavaller i protonotari Giacomo Pizzinga, capità de Milazzo, entre ז346 i ı376, amb les designacions següents: "Jacupum Pizinga de Messana, magistrum notarium nostre curie in officio cancellarie, consiliarium et fidelem nostrum” (I346?), "magistro Jacobo Picigna de Messana, magne sue curie actori magistro notario, cons. fid. et famil. suo" ( $3_{35} 2$ ?), "Jacobo Picigna, militi magne sue curie magistro notario et consiliario familiari et fideli suo" (s. d. [concessió de la capitania de Milazzo]), “Jacobus Picigna de Messana, miles, doctor magne nostre curie iusticie magister notarius, consiliarius, familiaris et fidelis noster” (I360), “magistro Jacobo Piccinga de Messana, magistro notario... in officio cancellarie cons. fam. et fid. suo" (1365), "magistro Jacobo Picigna de Messana, in officio cancellarie magistro notario, cons. fam. et fid. nostro" (I366-67), "magistri Jacobi Picigne de Messana, actorum magne curie magistri notarii, consiliaris, familiaris et fidelis nostri” ( $3_{367}$ ), “... et Jacobum Picigna, de dicta civitate, militem, actorum magne nostre curie magistrum notarium, familiares et fideles nostros” ( ${ }_{3} 67$ ) ), "Jacobinum Picigna de Messana, magne nostre curie magistrum notarium, consiliarem, familiarem et fidelem nostrum" (ı367), "magistro Jacobo Picigne, actorum magne nostre curie magistro notario" (i369), "Jacobo Picigne de Messana, militi, castellano et capitaneo terre et castri Melacii, cons. f. et f. nostro" (I374), "Jacobi Picigne de Messana, militi cons. fam. et fid. nostro" (I374), "Jacobo Picigna de Messana, militi, magistro nostre curie iusticie actorum magistro notario, fam. et fideli nostro" (I375), "Jacobum Picinga de Messana, militem, actorum magne nostre curie magistrum notarium, cons. fam. et fid. nostrum” ( 1376$)$. 
Martí i de Martí el Jove a partir de I392, estigué abans vinculat a la facció filocatalana de Guglielmo Peralta, i dedicà al seu fill Nicolò, creat comte de Caltabellotta el I39I, el tractat polític Viridarium principum, una compilació en què els exemples de la història antiga i les doctrines dels filòsofs pagans s'ofereixen com a model de virtuts del governant cristià (Ciccarelli 2003: 24-42; 2007: I3748). Però Andrea da Pace era també un lector de Dante, i cità els set primers versos de l'Inferno en un sermó per la nativitat de Crist (f. $\mathrm{IO}^{\mathrm{r}}$ ) recollit en les seves Introductiones dominicales (I39I-92 o poc després, sempre abans de 1397) ${ }^{6}{ }_{4}$

A la fi del període que ens ocupa, Dante havia arrelat profundament en la cultura siciliana. El I5 de desembre de I4I3, Martinu de Binidicti de Palerm, "pensandu aviri jo servutu anni XX la casa dArago", adreçà a Ferran I d'Antequera, "Rei di Arago et di Sikilia", una epístola de queixa contra els seus primers ambaixadors, citant com a conclusió una tercina de la Commedia (Purg. VI, II2-I4):

Viene a veder la tua Roma che piagni

vedova scura e di enocte brama

cesari mio per che non m.aconpagni. ${ }^{65}$

Tot indica que Sicília podria haver estat una de les principals vies de difusió de Dante en la cultura catalana al darrer terç del segle XIV. Com hem vist més amunt, la poesia d'Andreu Febrer testimonia l'existència d'una cort literària a la Sicília de Martí el Jove i de Maria pels volts I398-I4OO, en la qual s’imitava no solament el Dante de la Commedia sinó també el de les cançons (Torró 2OI4; CabréTorró 20I5). Gilabert de Pròixida, que serví a Sicília el I392 i el I394, es féu ressò de la Vita nova al voltant d'aquests anys. El desembarcament de 1392 hauria pogut obrir la porta d'accés a materials dantescos, com ara la silloge boccaccesca, que des del regnat de Frederic IV pogueren desvetllar l'interès de cancellers, juristes, notaris, nobles o, fins i tot, franciscans de tendències classicitzants, com Ubertino da Corleone o Ruggero da Eraclea, en contacte freqüent amb el regne de Nàpols o, fins i tot, directament amb Boccaccio. En tot cas, els poetes aplegats a l'entorn del duc de Montblanc i dels reis Martí I i Maria de Sicília haurien pogut considerar la imitació de Dante el millor signe d'identitat d'una cort i una cultura on el coneixement de Dante era ja antic, molt estès i profund.

Per descomptat, la silloge dantesca de Boccaccio hauria pogut arribar a la cort de Joan I abans de 1392 per unes altres vies, com ara Gènova, Bolonya o, fins i tot, Avinyó, però no en posseïm cap indici concret. D'altra banda, sabem que almenys un manuscrit de l'Inferno, potser amb glosses derivades de l'Ottimo commento, era conegut per Bernat Metge el ı38r quan componia el Llibre de Fortuna e Prudència. La seva procedència és, òbviament, incerta, però fins i tot en una data tan reculada és convenient de recordar els estrets lligams familiars i polítics que vinculaven les corts de

64. Andrea de Pace, ministre provincial de Sicília (I387-97), fou nomenat mestre capellà o capellà major de Martí i Martí el Jove el 29 de maig de i392, poc després del desembarcament a Palerm. "Le funzioni di maestro cappellano ricevute dal nuovo governo aragonese erano rilevanti, non solo perché gli attribuivano una giurisdizione esclusiva sulla cappella palatina e su tutte le cappelle reali e i regii cappellani, vale a dire su tutta quella parte del clero siciliano considerata politicamente fedele dal duca Martino e da lui favorita, con gli importanti redditi connessi alla carica, ma soprattutto perché ponevano Andrea da Sciacca in una posizione di vertice, in stretta vicinanza e collaborazione personale con il duca” (Fodale 2007: 445-46). Tot seguit, el juny de I392, passà a l'obediència del papa d'Avinyó, Climent VII. Confirmat en el càrrec de capellà major per Martí I el Jove, visqué a la cort de Catània fins que el març de I398, ja substituït per Joan Despí com a capellà major (Fodale 2007: 450), es traslladà a Barcelona com a ambaixador prop de Martí l'Humà, almenys fins al I4Or; aspirà als bisbats de Malta i de Catània, i morí poc després del I4O8. Una al-lusió recent als progroms hispànics de ı39ז en el sermó del cinquè diumenge després de Pentecosta convida a datar la redacció final de les Introductiones dominicales ja en el període de vinculació amb el rei Martí el Jove (Ciccarelli 2003: 19-24; 2007: 132-36).

65. Romano I980: I05. Agraeixo la referència a Raquel Parera. 


\section{Sicília i d'Aragó.}

El I349 Pere el Cerimoniós s’havia casat en terceres núpcies amb Elionor de Sicília, germana de Frederic, el qual al seu torn contragué matrimoni el I36r amb Constança, filla primogènita del rei Pere i de Maria de Navarra, primera muller del Cerimoniós. Constança morí el I363 arran del part de Maria de Sicília, hereva legítima del regne després de la mort de Frederic IV (I377) gràcies als drets successoris reconeguts pel tractat d'Avinyó de 20 d'agost de i372, que també consagrava la independència de la Sicília insular ("regne de Trinàcria") sota el domini feudal del papa. Durant tot el tercer quart del segle XIV fins a la seva mort (20 d'abril de I375), Elionor tingué un paper molt rellevant en la política siciliana d’Aragó, i ocupà el centre d'una xarxa de relacions que comprometien les dues branques de la dinastia.

Bernat Metge es formà en aquest ambient. Ell mateix es complau a recordar-ho per boca del rei Joan en el llibre segon de Lo somni, tot alegrant-se per la notícia de la salvació del rei Pere i de la reina Elionor: "ne has gran raó, car en lur casa est estat nodrit e n'has reebuts molts benificis e honor” (II,v,I3; Cingolani ed. 2006: I78). El pare de Bernat Metge, l'especier Guillem Metge, fou creat domèstic i familiar de la reina Elionor el 5 d'octubre de I356 (Riquer I959: * II i *2I5, doc. 4). El padrastre de Bernat, Ferrer Saiol -traductor al català (I385) de l'Opus agriculturae de Pal-ladi-, havia estat escrivà de ració de la reina almenys des del I359 i en fou protonotari a partir del ${ }_{3} 365$ (Cabré 2OI4: 192). Trobo que cal subratllar-ho: Ferrer Saiol, protonotari d’Elionor de Sicília, era l'homòleg de Giacomo Pizzinga, protonotari de Frederic IV durant tot el seu regnat. Ferrer Saiol introduí el fillastre Bernat Metge a la cancelleria d'Elionor com a ajudant de registre el I5 d'abril de I37I. Martí de Riquer (I959: * I7) recordava que "En la corte de la reina Leonor existía cierto interés por la literatura”, citant com a exemple un debat poètic de març de I374 (Rubió i Lluch I9o8-2I: I, 25I-54, doc. CCLXVI-CCLXIX; Riquer I954-56) que més aviat il-lustra les inquietuds culturals del primogènit: el príncep Joan hi participà molt activament, féu fer i distribuir còpia de totes les obres i, finalment, escrigué des de València a Ferrer Saiol perquè recollís els comentaris del rei i de la reina "e les persones notables que entorn d ells sien quant se ligiran" (Rubió i Lluch I9o8-2I: I, 254, doc. CCLXIX).

A parer meu, no és gens improbable que almenys l'Inferno de Dante, potser amb glosses derivades de l'Ottimo commento, fos conegut a la cort d'Elionor de Sicília i a l'entorn del seu protonotari Ferrer Saiol ( $1365-75)$, i que fins i tot fos objecte d'una lectura cortesana en clau amorosa i sentimental, en presència del príncep Joan i de Bernat Metge, pels volts de I375. Una reminiscència d'aquesta possible recepció és precisament el que podria documentar aquell primer ressò del cant de Paolo i Francesca en un context tan poc sentimental com és el Llibre de Fortuna e Prudència.

\section{Entre Sicília i Barcelona}

E 1 Llibre de Fortuna e Prudència proporciona la prova que el r38i Bernat Metge coneixia si més no l'Inferno de Dante, probablement amb glosses derivades de l'Ottimo commento. L'origen d'aquest coneixement és incert, però és possible que un manuscrit de Dante hagués arribat a la cort de la reina Elionor abans de I375, procedent de la del seu germà, Frederic IV de Sicília. Personatges d'un perfil professional i intel-lectual com Ferrer Saiol o Giacomo Pizzinga, protonotaris de la cancelleria de l'una i de l'altre, podrien haver exercit una funció rellevant com a transmissors, però és una hipòtesi que no podem fonamentar més que en indicis circumstancials. Frederic IV posseïa l'Inferno el I367, i el I377 també consta en l'inventari de béns del franciscà Matteo della Porta, arquebisbe de Palerm. El franciscà Ruggero da Eraclea al·lega Dante profusament en el Quadragesimale scolarum 
(Ia red. I367/68; 2 a red. poc posterior), i un altre franciscà anònim també en calca els versos en la Sposizione del Vangelo della Passione secondo Matteo (I373). Certament, la lectura de la Commedia, amb o sense l'assistència de glosses, era reservada a lectors amb una bona instrucció gramatical, religiosos o oficials de la cancelleria. No obstant això, en una cort com la d'Elionor de Sicília, o com la del príncep Joan, el cant de Paolo i Francesca era susceptible d'una lectura cortesana en clau sentimental, de la qual podria donar testimoniatge un ressò literal (Inf. V, I2I-23) en els versos 46063 del Llibre de Fortuna e Prudència, mentre que el personatge del vell, potser concebut a partir de la glossa de l'Ottimo a una menció de Diògenes (Inf. IV, I37), podria constituir la primera mostra d'influència de la crítica dantesca en la nostra literatura. No sabem si en aquest temps hom coneixia el conjunt de la Commedia ni altres textos de Dante, com ara la Vita nova o la quinzena de canzoni de l'anomenada silloge boccaccesca.

Tot aquest corpus era, però, ben conegut al tombant de segle entre poetes adscrits a la cort de Joan I i que, d'una manera o altra, participaren en la política mediterrània liderada per Martí. El futur traductor de la Commedia (I429) per a Alfons el Magnànim, Andreu Febrer, format com a escrivà a la cancelleria de Joan I, i cambrer de Martí el Jove des del març de I398, demostra conèixer la Commedia, les petrose C i CI, i potser també la Vita nova. El cavaller Gilabert de Pròixida, talladorer de Joan I, que combaté a Sicília el I392 i el I394, i que morí el I4O5, evoca el motiu de la donna schermo i el sonet "Tanto gentile" de la Vita nova, també reprès repetidament pel patró de naus barceloní Melcior de Gualbes -talladorer de Joan I el I395 i mort abans de I4I5-, en un corpus molt breu en què ressonen la cançó L de Dante i molts estilemes de Petrarca i dels estilnovistes.

En el terreny cultural, els reis Joan i Martí revitalitzaren la pròpia tradició lírica, d’arrel trobadoresca, impulsant el Consistori de la Gaia Ciència de Barcelona: Gilabert de Pròixida potser hi concorregué l’any de la seva institució (I393) amb la cançó “Le sovenirs” (VI), i Andreu Febrer ho podria haver fet l'any de la seva refundació (I398) amb “Sobre.l pus naut” (I), un exaltat panegíric de Maria de Sicília, d’inspiració dantesca. Si Joan I i Violant de Bar propiciaren la imitació de Guillaume de Machaut i de la lírica francesa, és possible que el mateix Joan i, sobretot, Martí encoratgessin la imitació de la lírica italiana i, especialment, de Dante: un lectura associada al record d'Elionor de Sicília i de Frederic IV, i potser també familiar a la seva filla, la reina Maria de Sicília -tot i la seva presumiblement escassa formació-, que a partir del desembarcament de I392 podia esdevenir un emblema d'identitat i de continuïtat cultural al servei de la legitimació de la dinastia catalana. Des de les Introductiones dominicales del franciscà Andrea da Pace (I39I/92, abans de I397) fins a la carta de queixa de Martinu de Binidicti contra els ambaixadors de Ferran d'Antequera (I4I3), Dante es revela un referent estable de la cultura siciliana.

L'existència d'aquest lligam amb Sicília no permet de tancar altres possibles vies de difusió de la Commedia, del Dante líric i de la crítica dantesca, com ara Gènova, Bolonya o, fins i tot, Avinyó, tot i la manca indicis. Només podem intuir que, prop de la cúria papal d’Avinyó, Bernat Metge pogué adquirir el I395 algunes de les novetats de Petrarca i de Boccaccio que incorporà a la composició de Lo somni (c. I398). En aquesta obra hi són segures, i molt significatives, les aportacions de la Commedia i de la Genealogia deorum gentilium de Boccaccio, mentre que tot just s'hi detecta algun possible ressò de la Vita nova o, més dubtosament, de les Esposizioni sopra la Commedia del mateix Boccaccio, de difusió molt exigua. L'inventari de la biblioteca de Benet XIII a Peníscola (c. I420) testimonia l'interès del papa per adquirir en aquella data tant la traducció llatina de Giovanni da Serravalle com el comentari de Benvenuto da Imola, però són incerts tant el lloc com la data d'adquisició de l'únic exemplar de la Commedia que hi consta. En aquest cas particular no es pot excloure, entre d'altres, la via de la Ligúria, on Benet XIII sojornà abans d'establir-se permanentment a Catalunya el I 409 .

És possible que la difusió de Dante a les corts de França fos més antiga i extensa del que 
permeten de sospitar els pocs indicis detectats fins avui. El I389 Philippe de Mézières es fa ressò d'una diatriba dantesca contra els genovesos en el Songe du vieil pèlerin, però el pare de Christine de Pizan, el metge i astròleg bolonyès Tommaso di Benvenuto da Pizzano, s'havia incorporat a la cort de Carles V el ı369; podem afirmar, doncs, que almenys un manuscrit de la Commedia degué arribar a París entre I369 i r38o. Christine de Pizan cita, imita i menciona Dante reiteradament entre els anys I4OI-I4O5, i en la conclusió de la seva controvèrsia sobre el Roman de la Rose (I4OII4O2) recomana expeditivament a Pierre Col la lectura de la Commedia. A la cort de Berry, el I4O9 Laurent de Premierfait potser coneix el Trattatello in laude di Dante de Boccaccio. El nom de Dante fou, per tant, conegut a la cort reial de França des de les darreres dècades del segle XIV, però fou sobretot a la primeria del Xv que Christine de Pizan contribuí poderosament al seu prestigi tant a la cort com a la universitat. Fou precisament entre I4O4 i I 407 que el mestre en arts Felip de Malla, posseïdor de la Commedia i del Roman de la Rose segons l’inventari pòstum dels seus béns (I43I), estudià a París fins a rebre el magisteri en teologia. Tot i que Felip de Malla hauria pogut conèixer la Commedia abans d'arribar a París, és gairebé segur que en aquella primera dècada del segle XV la va llegir en aquest nou context cortesà i universitari. El I4II citava Dante a Barcelona en un solemne sermó de santa Eulàlia, $\mathrm{i}$ ho tornà a fer el I4I3 en els sermons que pronuncià en la represa del Consistori de la Gaia Ciència - una de les primeres iniciatives culturals adoptades pel primer rei de la nova dinastia Trastàmara, Ferran d’Antequera, potser assessorat per Enric de Villena. Perfectament en la línia d’Andreu Febrer i el seu elogi de Maria de Sicília, Felip de Malla hi proposà als "trobadors estudiosos" el panegíric de la monarquia com a tema, i Dante, Jean de Meun i Arnaut Daniel com a models d'una "gaia ciència" veritablement digna d'aquest nom.

Quan el 20 de febrer I408 el rei Martí -amb o sense l'assitència dels seus secretaris, Joan de Tudela i Bernat Metge- esmentà el nom de Dante en la seva carta a Guerau Alemany de Cervelló, prop de Benet XIII a Savona, resumint-li irònicament una glossa relativa a l'oracle de la Sibil.la (Par. XXXIII, 65-66), el rei demostrava que Dante, la Commedia i la seva exegesi havien esdevingut una fita ferma en l’horitzó referencial dels catalans cultes. 


\section{${ }_{7}$ Obres citades}

Alberni, Anna. 2002. 'El cançoner Vega-Aguiló: una proposta de reconstrucció codicològica', in Literatura i cultura a la Corona d'Aragó, ed. by Lola Badia, Miriam Cabré, and Sadurní Martí, Textos i Estudis de Cultura Catalana, 85 (Barcelona: Publicacions de l'Abadia de Montserrat; Curial), pp. I5 ${ }^{\mathrm{I}-7 \mathrm{I}}$

Alberni, Anna. 2005. 'Gilabert de Pròixida, poeta cortesà al servei del Casal d'Aragó', in Actes del X Congrés Internacional de l'Associació Hispànica de Literatura Medieval, ed. by Rafael Alemany, Josep Lluís Martos, and Josep Miquel Manzanaro (Alacant: Institut Interuniversitari de Filologia Valenciana), I, 227-40

Alberni, Anna. 20Io. 'Guillaume de Machaut en la tradició catalana dels segles XIV-XV: la suite d'esparses del cançoner VeAg', in Translatar i transferir. La transmissió dels textos $i$ el saber (1200-1500), ed. by Anna Alberni, Lola Badia, and Lluís Cabré (Santa Coloma de Queralt: Obrador Edèndum; Tarragona: Publicacions URV), pp. 317-47

Alberni, Anna. 20I2. 'El Roman de Cardenois i l'empremta de Guillaume de Machaut en la poesia catalana medieval', Romania, I30.I-2: 74-I08

Arce, Joaquín. I965. 'La bibliografía hispánica sobre Dante y España entre dos centenarios (I92II965)', in Dante nel mondo, ed. by V. Branca and E. Caccia (Firenze: Olschki), pp. 4O7-3I

Arce, Joaquín. 1976. 'Fortuna di Dante in Spagna', in Enciclopedia Dantesca, 2nd edn (Roma: Istituto della Enciclopedia Italiana), v, 355-62

Arduini, Beatrice; Wayne Storey, Harry (ed.). 20o6. 'Edizione diplomatico-interpretativa della lettera di frate Ilaro (Laur. XXIX 8, c. 67r)', Dante Studies, I24: 77-89

Auvray, Lucien. I892. Les Manuscrits de Dante des bibliothèques de France (Paris: Ernest Thorin)

Auzzas, Ginetta (ed.). 1992. Giovanni Boccaccio Epistole e lettere, in Tutte le opere di Giovanni Boccaccio, ed. by V. Branca (Milano: Mondadori), vol. 5.I

Badel, Pierre-Yves. 197. ' '[À propos de la connaissance de Dante en France]', Cahiers de l'Association Internationale des Études Françaises, 23: 334

Badia, Lola. I99I-92. 'Bernat Metge i els auctores: del material de construcció al producte elaborat', Boletín de la Real Academia de Buenas Letras de Barcelona, 43: 25-40

Badia, Lola. I997. 'Fa che tu scrive: variaciones profanas sobre un motivo sagrado, de Ramon Llull a Bernat Metge', in The Medieval Mind. Hispanic Studies in Honour of Alan Deyermond, ed. by Ian Macpherson and Ralph Penny (London: Tamesis), pp. 3-2O

Balasch, Manuel (ed.). I98I-86. Felip de Malla Memorial del pecador remut: manuscrit de Barcelona [= Primera part], 3 vols, Els Nostres Clàssics A, ıI8, ıI9 i I23 (Barcelona: Barcino)

Batard, Yvonne. 1975: 'Christine de Pisan (1364-I430)', in Dante nel pensiero e nella esegesi dei secoli XIV e XV. Atti del III Congresso Nazionale di Studi Danteschi (Melfi, 27 Settembre - 2 Ottobre 1970) (Firenze: Olschki), pp. 27I-76

Bellomo, Saverio. 2004a. Dizionario dei commentatori danteschi: l'esegesi della 'Commedia' da Iacopo Alighieri a Nidobeato, Biblioteca di Lettere Italiane - Studi e Testi, 62 (Firenze: Olschki) 
Bellomo, Saverio. 2004b. 'Il sorriso di Ilaro e la prima redazione in latino della Commedia', Studi sul Boccaccio, 32: 2OI-35

Billanovich, Giuseppe. r947a. 'La leggenda dantesca del Boccaccio: dalla Lettera di Ilaro al Trattatello in laude di Dante', in Prime ricerche dantesche (Roma: Storia e Letteratura), pp. 2I-86

Billanovich, Giuseppe. 1947b. Petrarca letterato (Roma: Storia e Letteratura), I: Lo scrittoio del Petrarca

Boni, Marco. I967. 'La prima segnalazione di Dante in Spagna', in Dante e Bologna nei tempi di Dante, ed. by Facoltà di Lettere e Filosofia dell’Università di Bologna (Bologna: Commissione per i Testi di Lingua), pp. 389-402

Borghezio, Gino; Fasola, Cesare. 1921. 'Dante nella Libreria di Ludovico di Savoia (I434)', Bollettino Storico-bibliografico Subalpino, 23: 453-6I

Branca, Vittore. 1958-9I. Tradizione delle opere di Giovanni Boccaccio, 2 vols (Roma: Edizioni di Storia e Letteratura)

Branca, Vittore (ed.). 1992. Giovanni Boccaccio Decameron, 2 vols (Torino: Einaudi) (Ist edn I98o)

Bresc, Henri. I97. Livre et société en Sicile (1299-1499) (Palermo: n.p.)

Cabré, Lluís. 2005-2006. 'Orfeu a Lo somni: el gust per la poesia', Butlletí de la Reial Acadèmia de Bones Lletres de Barcelona, 50: 249-70

Cabré, Lluís. 2006. 'Bernat Metge, Reader and Translator of Jean de Meun and Alain de Lille', in Latin and Vernacular in Renaissance Iberia, II: Translations and Adaptations, ed. by Barry Taylor and Alejandro Coroleu (Manchester: Manchester Spanish \& Portuguese Studies), pp. I-I2

Cabré, Lluís. 2007. 'Andreu Febrer, fabbro i lector', in From the 'Cancionero de Baena' to the 'Cancionero general': Studies in Honour of Jane Whetnall, ed. by Alan Deyermond and Barry Taylor, Papers of the Medieval Hispanic Research Seminar, 6o (London: Queen Mary University of London), pp. IO3-I4

Cabré, Lluís (ed.). 20Io. Bernat Metge Llibre de Fortuna i Prudència, Els Nostres Clàssics B, 30 (Barcelona: Barcino)

Cabré, Lluís. 2012. 'Petrarch’s Griseldis from Philippe de Mezières to Bernat Metge', in CabréCoroleu-Kraye ed. 20I2, pp. 29-42

Cabré, Lluís. 20I4. 'Bernat Metge', in Història de la literatura catalana, ed. by Àlex Broch (Barcelona: Enciclopèdia Catalana; Editorial Barcino; Ajuntament de Barcelona), II: Literatura medieval (II): segles XIV-XV, ed. by Lola Badia, pp. I85-238

Cabré, Lluís; Coroleu, Alejandro; Kraye, Jill (ed.). 20I2. Fourteenth-Century Classicism: Petrarch and Bernat Metge, Warburg Institute Colloquia, 2I (London: The Warburg Institute; Torino: Nino Aragno Editore)

Cabré, Lluís; Ferrer, Montserrat. 2012. 'Els llibres de França i la cort de Joan d’Aragó i Violant de Bar', in El saber i les llengües vernacles a l'època de Llull i Eiximenis: estudis ICREA sobre vernacularització, ed. by Anna Alberni, Lola Badia, Lluís Cifuentes, and Alexander Fidora, Textos i Estudis de Cultura Catalana, I7o (Barcelona: Publicacions de l'Abadia de Montserrat), pp. $2 \mathrm{I} 7-3 \mathrm{O}$

Cabré, Lluís; Torró, Jaume. 20I5. 'La poesia d’Andreu Febrer: el trobar ric i el Dante líric', Medioevo Romanzo, 39.I: I52-65 
Camus, Jules. I9or. 'La première version française de l'Enfer de Dante: Notes et observations', Giornale Storico della Letteratura Italiana, 37.I: 70-93

Casadei, Alberto. 20II. 'Considerazioni sull'epistola di Ilaro', Dante: Rivista Internazionale di Studi su Dante Alighieri, 8: II-2I

Casas Homs, Josep Maria (ed.). I956. Lluís d’Averçó Torcimany, 2 vols (Barcelona: CSIC; Instituto Miguel de Cervantes Sección de Literatura Catalana)

Casella, Mario. 1966. 'El Somni d'En Bernat Metge e i primi influssi italiani sulla letteratura catalana', in Saggi di letteratura provenzale e catalana, ed. by G. Sansone (Bari: Adriatica), pp. I67-243 (Ist edn Archivum Romanicum, 3 [ı919]: I45-205)

Cenci, Cesare. 1995: 'Il Quaresimale delle scuole di fr. Ruggero da Eraclea', Archivum Franciscanum Historicum, 88: 269-318

Ciccarelli, Diego. 1987. 'Studia, maestri e biblioteche dei Francescani di Sicilia (sec. XIII-XVI)', in Musco ed. 1987, pp. I8I-207

Ciccarelli, Diego (ed.). 2003. Andreas de Pace O. Min. Viridarium principum: Il giardino dei principi, Franciscana, 9 (Palermo: Biblioteca Francescana; Officina di Studi Medievali)

Ciccarelli, Diego. 2007. 'Il Viridarium principum di Andrea de Pace, O.Min.', in Musco ed. 2007, pp. $125-48$

Cingolani, Stefano M. I999. 'Lo somni de Bernat Metge: prolegòmens per a una nova edició', Llengua \& Literatura, IO: 245-78

Cingolani, Stefano M. 2002. El somni d'una cultura: 'Lo somni' de Bernat Metge, Assaig, 33 (Barcelona: Quaderns Crema)

Cingolani, Stefano M. (ed.). 20o6. Bernat Metge Lo somni, Els Nostres Clàssics B, 27 (Barcelona: Barcino)

Coopland, George William (ed.). r969. Philippe de Mézières Le Songe du Vieil Pèlerin (Cambridge: Cambridge University Press)

Correnti, Santi. 1979. Dante e la Sicilia (Catania: Edizioni Greco)

Delisle, Léopold. 19O7. Recherches sur la librairie de Charles V(Paris: Honoré Champion)

De Robertis, Domenico (ed.). 2002. Dante Alighieri Rime, 3 vols (Firenze: Le Lettere)

De Robertis, Domenico (ed.). 2005. Dante Alighieri Rime, Archivio Romanzo, 7 (Firenze: Edizioni del Galluzzo per la Fondazione Ezio Franceschini) [Edició comentada del text establert per De Robertis ed. 2002]

De Stefano, Antonio. 1957. 'Jacopo Pizzinga protonotaro e umanista siciliano del sec. XIV', Bollettino del Centro di Studi Filologici e Linguistici Siciliani, 5: 183-97

Di Girolamo, Costanzo. 2003. 'La Versification catalane médiévale entre innovation et conservation de ses modèles occitans', Revue des Langes Romanes, IO7: 4I-72

Di Girolamo, Costanzo; Siviero, Donatella. 1999. 'Da Orange a Beniarjó (passando per Firenze): un'interpretazione degli estramps catalani', Revue d'Études Catalanes, 2: 8I-95 [Trad. cat.: 'D’Orange a Beniarjó (passant per Florència): una interpretació dels estramps catalans', Mot So Razo, I (I999), 32-39] 
Di Stefano, Giuseppe. 1974. 'Alain Chartier, ambassadeur à Venise', in Culture et politique en France à l'époque de l'Humanisme et de la Renaissance: Atti del convegno internazionale promosso dall'Accademia delle scienze di Torino in collaborazione con la Fondazione Giorgio Cini di Venezia (29 marzo-3 aprile 1971), ed. by Franco Simone (Torino: Accademia delle Scienze), pp. I $55^{-68}$

Durrieu, Paul. I92I. 'Dante et l'art français du XV siècle', Comptes rendus des séances de l'Académie des Inscriptions et Belles-Lettres, 65·3: 214-24

Epalza, Mikel de (ed.). 1978. Anselm Turmeda Autobiografia i atac als partidaris de la Creu (Barcelona: Curial)

Epalza, Mikel de (ed.). 1994. Fray Anselm Turmeda ('Abdallâh al-Taryumân) y su polémica islamocristiana: edición, traducción y estudio de la 'Tuhfa', 2nd edn (Madrid: Hiperión) (Ist edn I97I)

Espadaler, Anton M. 20I5. 'Petrarca en la lírica catalana medieval', Quaderns d'Italià, 20: 89-Io9

Faccioli, E. (ed.). 1970. Franco Sacchetti Il Trecentonovelle (Torino: Einaudi) < http://www. letteraturaitaliana.net/pdf/Volume 2/t46.pdf>

Farinelli, Arturo. I9O2-I9O5. 'Appunti su Dante in Ispagna nell'Età Media', Giornale Storico della Litteratura Italiana, Supl. 8: I-IO4

Farinelli, Arturo. 1905. 'Dante nell'opera di Christine de Pisan', in Aus Romanischen Sprachen und Literaturen: Festschrift Heinrich Morf (Halle: Niemeyer), pp. II7-52

Farinelli, Arturo. I908. Dante e la Francia dall'età media al secolo di Voltaire, 2 vols (Milano: Hoepli)

Farinelli, Arturo. 1922. Dante in Spagna, Francia, Inghilterra, Germania (Dante e Goethe) (Torino: Bocca)

Faucon, Maurice. I886-87. La librairie des Papes d'Avignon: sa formation, sa composition, ses catalogues (1316-1420), 2 vols (Paris: E. Thorin)

Fera, Vincenzo. 2005. 'Versi di Giacomo Pizzinga contro la Sicilia', in Margarita amicorum: studi di cultura europea per Agostino Sottili, ed. by Fabio Forner, Carla Maria Monti, and Paul Gerhard Schmidt (Milano: Vita e Pensiero), I, 283-90

Ferrer, Montserrat. 20I2. 'Petrarch's Africa in the Aragonese Court: Anníbal e Escipió by Antoni Canals', in Cabré-Coroleu-Kraye ed. 20I2, pp. 43-55

Fleming, John. 1982. 'The Major Source of Bernat Metge's Libre de Fortuna e Prudència', Journal of Hispanic Philology, 7: 5-I3

Fodale, Salvatore. 1987. 'I frati minori in Sicilia tra i Martini e lo scisma (I392)', in Musco ed. I987, pp. $79^{-8} 5$

Fodale, Salvatore. 2007. 'Fra' Andrea de Pace da Sciacca', in Musco ed. 2007, pp. 443-52

Frati, Ludovico. I89o. 'Inventario della biblioteca francescana di Bologna (I42I)', Miscellanea Francescana, 5.4: $110-20$

Friederich, Werner P. 1950. 'Dante in Spain', in Dante's Fame Abroad (1350-1850): The influence of Dante Alighieri on the poets and scholars of Spain, France, England, Germany, Switzerland and the United States (Roma: Edizioni di Storia e Letteratura), pp. I3-56

Gallina, Annamaria (ed.). 1974-88. Dant Alighieri Divina Comèdia: versió catalana d’Andreu Febrer, 
Els Nostres Clàssics A, IO6-IO7-II2-II6-I2O-I24, 6 vols (Barcelona: Barcino)

Gaudioso, Matteo. 193I. 'Frammenti di un Codice trecentesco del Paradiso di Dante in Catania', Archivio Storico per la Sicilia Orientale, 27: 65-75

Giannini, Alfredo. I92 гa. Dante in Catalogna (Napoli: C.U.F. Razzi)

Giannini, Alfredo. I92 Ib. 'La fortuna di Dante nel mondo: VII, In Spagna', L'Italia che scrive, 4.I2: $237^{-38}$

Giuffrida, Romualdo. 1969. 'Frammenti di un codice trecentesco della Commedia scoperti nell'Archivio di Stato di Trapani', Bollettino: Centro di Studi Filologici e Linguistici Siciliani, Io: 385-95

Giunta, Francesco; Giuffrida, Romualdo; Sparti, Aldo (ed.). 1983. Dante e la Sicilia: frammenti di un codice trecentesco della Commedia conservati a Trapani (Palermo: Accademia di Scienze, Lettere e Arti di Palermo)

Gómez, Francesc J. 2002. 'L'ofici del poeta segons Orfeu: una clau hermenèutica per a Lo somni de Metge?', in Literatura i cultura a la Corona d'Aragó, ed. by Lola Badia, Miriam Cabré, and Sadurní Martí, Textos i Estudis de Cultura Catalana, 85 (Barcelona: Publicacions de l'Abadia de Montserrat; Curial), pp. $63-85$

Gómez, Francesc J. 2009-Io. 'Revelació i testimoniatge en Lo somni: models sacres i proemials', Butlletí de la Reial Acadèmia de Bones Lletres de Barcelona, 52: 2I-5O

Gómez, Francesc J. 2оіо. 'Ficció i heterodòxia en Lo somni de Bernat Metge a la llum del Liber de spiritu et anima', Llengua \& Literatura, 2I: 7-54

Gómez, Francesc J. 20I4. El 'Tractat de les penes particulars d'infern' de Joan Pasqual: estudi i edició crítica (unpublished doctoral thesis, Universitat de Girona)

Gómez, Francesc J. 20I6. "Lo Dant o la glosa”: aparats exegètics de la Commedia en la Catalunya de mitjan segle XV', in Els manuscrits, el saber i les lletres a la Corona d'Aragó (1250-150o), ed. by Lola Badia, Lluís Cifuentes, Sadurní Martí, and Josep Pujol, Textos i Estudis de Cultura Catalana, 2Io (Barcelona: Publicacions de l'Abadia de Montserrat), pp. I6I-94

Grifoll, Isabel. 2006. "Combas e valhs, puigs, muntanyes e colhs": Andreu Febrer i els trobadors', in Trobadors a la península Ibèrica: homenatge al Dr. Martí de Riquer, ed. by Vicenç Beltran, Meritxell Simó, and Elena Roig (Barcelona: Publicacions de l’Abadia de Montserrat), pp. I95-22I

Grimaldi, Marco. 2014. 'Boccaccio editore delle canzoni di Dante', in Boccaccio editore e interprete di Dante: atti del Convegno internazionale di Roma (28-30 ottobre 2013), ed. by Luca Azzetta and Andrea Mazzucchi (Roma: Salerno Editrice), pp. I37-57

Hamilton, G. L. I9or. 'Notes on the Latin Translation of, and Commentary on the Divina Commedia by Giovanni da Serravalle', Annual Reports of the Dante Society, 20: I5-37

Hicks, Eric (ed.). 1977. Christine de Pisan - Jean Gerson - Jean de Montreuil - Gontier et Pierre Col Le Débat sur le 'Roman de la Rose', Bibliothèque du XV siècle, 43 (Paris: Honoré Champion)

Indizio, Giuseppe. 20o6a. 'Dante e l'enigma del monaco Ilaro di S. Croce: contributo per una vexata quaestio', Dante Studies, I24: 9I-II8

Indizio, Giuseppe. 2006b. 'L'Epistola di Ilaro: un contributo sistemico', Studi Danteschi, 7I: I9I263 
Labate, Valentino. I9oo. 'La prima conoscenza della Divina Commedia in Sicilia', Giornale Storico della Letteratura Italiana, I8.35: 339-53

Leonardi, Lino. 2004. 'Nota sull'edizione critica delle Rime di Dante a cura di Domenico De Robertis', Medioevo Romanzo, 28: 63-II3

Livi, Giovanni. rgı. Dall'archivio di Francesco Datini, mercante pratese (Firenze: F. Lumachi)

Livi, Giovanni. I9II. 'L'archivio di Francesco Datini, mercante toscano del secolo XIv', Anuaride l'Institut d'Estudis Catalans, 3.MCMIX-X: 203-209

Lo Forte Scirpo, Maria Rita. 2003. C'era una volta una regina... Due donne per un regno: Maria d'Aragona e Bianca di Navarra, Nuovo Medioevo, 67 (Napoli: Liguori)

Madurell i Marimon, Josep Maria. I963-64. 'Mestre Felip de Malla', Boletín de la Real Academia de Buenas Letras de Barcelona, 30: 499-626

Malato, Enrico; Mazzucchi, Andrea (ed.). 2OII. Censimento dei commenti danteschi, 2 vols (Roma: Salerno Editrice), I: I commenti di tradizione manoscritta (fino al 1480)

Marfany, Marta. 20I2. 'La influència de la poesia francesa d'Andreu Febrer a Ausiàs March', Estudis Romànics, 34: 259-87

Mathieu-Castellani, Gisèle. 20O4. 'Échos de Dante dans la poésie française du XVI siècle’, Littérature, I33.I: 40-53

Merkel, Maria. r92г. 'Le 'Chemin de long estude': primo tentativo di imitazione dantesca in Francia', Rassegna Nazionale, 2nd ser, 32: I89-2II, 243-58

Milà i Fontanals, Manuel. ı89o. Obras completas (Barcelona: Álvaro Verdaguer), III

Molas, Joaquim, I955. 'Sobre la composición X de Gilabert de Próxita', Revista de Literatura, 8: 90-97

Mombello, Gianni. 197I. 'I manoscritti delle opere di Dante, Petrarca e Boccaccio nelle principali librerie francese del secolo XV in Francia', in II Boccaccio nella cultura francese: atti del Convegno di Studi 'L'opera del Boccaccio nella cultura francese' (Certaldo, 2-6 settembre 1968) (Firenze: n.p.), pp. 8I-209

Monfrin, Jacques. 196r. 'La Bibliothèque de Matteo della Porta, archevêque de Palerme (I366-I377) et la question de la Sposizione del Vangelo della Passione secondo Matteo', Italia Medioevale e Umanistica, 4: 223-5I

Montoliu, Manuel de. I9ı6. 'Un nou poeta català medieval', Estudis Romànics: Llengua i Literatura, Biblioteca Filològica de l’Institut de Llengua Catalana, 6 (Barcelona: Institut d'Estudis Catalans, Palau de la Diputació) I, 29-4I

Montoliu, Manuel de. 1923. 'Las poesías líricas de Andreu Febrer', Revue Hispanique, 57: $36-98$

Moorman, John R. H. I947. 'The Foreign Element among the English Franciscans', The English Historical Review, 62.244: 289-303

Morel, Camille (ed.). I897. Les plus anciennes traductions françaises de la 'Divine Comédie' de Dante (Paris: Librairie Universitaire)

Musco, Alessandro (ed.). 1987. Francescanesimo e cultura in Sicilia (secc. XIII-XVI): atti del Convegno internazionale di studi nell'ottavo centenario della nascita di S. Francesco d'Assisi (Palermo, 7-12 marzo 1982), Franciscana, 2 (Palermo: Officina di Studi Medievali) 
Musco, Alessandro (ed.). 2007. I francescani e la politica: atti del Convegno internazionale di studio (Palermo 3-7 dicembre 2002), 2 vols, Franciscana, I3 (Palermo: Biblioteca Francescana; Officina di Studi Medievali)

Natoli, Luigi. 1893. Gli studi danteschi in Sicilia: saggio storico-bibliografico (Palermo: Lo Statuto)

Nepaulsingh, Colbert. 1977. 'Bernat Metge's Libre de Fortuna e Prudència and the Literary Tradition of the Goddess Fortuna', in Catalan Studies / Estudis sobre el català: Volume in Memory of Josephine de Boer, ed. by Joseph Gulsoy and Josep M. Sola-Solé (Barcelona: Hispam), pp. $203-2 \mathrm{I} 2$

Nicolau d'Olwer, Lluís. r9o8. 'Apunts sobre l’influencia italiana en la prosa catalana', Estudis Universitaris Catalans, 2: I66-79

Nicolini, Elena. I94I. 'Cristina da Pizzano: l'origine e il nome', Cultura Neolatina, I.2: I43-50

Olivar, Marçal (ed.). r927. Bernat Metge - Anselm Turmeda Obres menors, Els Nostres Clàssics A, IO (Barcelona: Barcino)

Padoan, Giorgio. I97I. 'Ilaro', in Enciclopedia Dantesca, 2nd edn (Roma: Istituto della Enciclopedia Italiana), III, 36I-63

Padoan, Giorgio (ed.). 1994. Giovanni Boccaccio Esposizioni sopra la Commedia di Dante, Oscar Classici, 242 (Milano: Mondadori) (Ist edn I965)

Padoan, Giorgio. 1993. Il lungo cammino del 'poema sacro's studi danteschi (Firenze: Olschki)

Pagès, Amadée. 1936. La poésie française en Catalogne du XIIIe siècle à la fin du Xve (Toulouse: Privat; Paris: Didier)

Palumbo, Pietro (ed.). 1954-57. Sposizione del Vangelo della Passione secondo Matteo, Collezione di Testi Siciliani dei Secoli XIV e XV, 4-8-9, 3 vols (Palermo: Centro di Studi Filologici e Linguistici Siciliani)

Palumbo, Giuseppe. 1967. 'Il codice 492 della Biblioteca di S. Francesco nella Comunale di Assisi', in Dante e l'Italia meridionale: atti del Congresso nazionale di studi danteschi (CasertaBenevento-Cassino-Salerno-Napoli, 10-16 ottobre 1965), ed, by Antonio Bacci et al. (Firenze: Olschki), pp. 463-78

Parera, Raquel. 2006. La versió d'Andreu Febrer de la 'Commedia' de Dante: estudi del manuscrit $i$ edició de l'Infern, I-XI (unpublished dissertation, Universitat Autònoma de Barcelona)

Parera, Raquel. 20Io. 'La versió d'Andreu Febrer de la Commedia de Dante: recursos del traductor', in Translatar i transferir: La transmissió dels textos i el saber (1200-1500), ed. by Anna Alberni, Lola Badia, and Lluís Cabré (Santa Coloma de Queralt: Obrador Edèndum; Tarragona: Publicacions URV), pp. I6I-I78

Parussa, Gabriella (ed.). 1999. Christine de Pizan Epistre Othea, Textes Littéraires Français, 5I7 (Genève: Droz)

Perarnau, Josep (ed.). r978. Felip de Malla Correspondència política, Els Nostres Clàssics A, II4 (Barcelona: Barcino)

Perarnau, Josep. 1987. 'Els inventaris de la biblioteca papal de Peníscola a la mort de Benet XIII', 'Darrer inventari de la biblioteca papal de Peníscola (I423)', 'Darrer inventari de la biblioteca privada de Benet XIII (I423)', 'Taules dels dos inventaris', Arxiu de Textos Catalans Antics, 6: 7-48, 49-183, I85-226, 227-295 
Petrocchi, Giorgio (ed.). I994. Dante Alighieri La 'Commedia'secondo l'antica vulgata, Le Opere di Dante Alighieri - Edizione Nazionale a cura della Società Dantesca Italiana, 7, 2nd edn, 4 vols (Firenze: Le Lettere) (ist edn I966-67)

Petroni, Liano. 1967. 'La prima segnalazione di Dante in Francia', in Dante e Bologna nei tempi di Dante, ed. by Facoltà di Lettere e Filosofia dell'Università di Bologna (Bologna: Commissione per i Testi di Lingua; Comitato Nazionale per le Celebrazioni del VII Centenario della nascita di Dante), pp. $375^{-8} 7$

Piacentini, Angelo. 20I4. 'Il carme Ytalie iam certus honos di Giovanni Boccaccio', in Boccaccio editore e interprete di Dante: atti del Convegno internazionale di Roma (28-3o ottobre 2013), ed. by Luca Azzetta and Andrea Mazzucchi (Roma: Salerno Editrice), pp. I84-2I6

Piana, Celestino. 1970. Chartularium Studï Bononiensis S. Francisci (saec. XIII-XVI), Analecta Franciscana, II (Quaracchi: Collegio S. Bonaventura)

Post, Chandler Rathfon. r9o8. 'The Beginnings of the Influence of Dante in Castilian and Catalan Literature', in Twenty-sixth Annual Report of the Dante Society (Cambridge, Mass.), 1907 (Boston: Gin \& Company), pp. I-59

Pujol, Josep, I988-89. 'Els versos estramps a la lírica catalana medieval', Llengua \& Literatura, 3: $4^{\mathrm{I}-87}$

Pujol, Josep. 1993-94. 'La “poètica nau de l'enteniment” i el naufragi d'Ulisses: opinions, teologia i poesia a l'obra de Felip de Malla', Boletín de la Real Academia de Buenas Letras de Barcelona, 44: 275-302

Pujol, Josep. 1994a. 'Els “trobadors estudiosos”' segons Felip de Malla', in La cultura catalana tra l'Umanesimo e il Barocco: atti del V Convegno dell'Associazione Italiana di Studi Catalani (Venezia, 24-27 marzo 1992), ed. by Carlos Romero and Rossend Arqués (Padova: Programma), pp. 19I-208

Pujol, Josep. 1994b. "Gaia vel gaudiosa, et alio nomine inveniendi scientia”: les idees sobre la poesia en llengua vulgar als segles XIV i Xv', in Intel-lectuals i escriptors a la baixa edat mitjana, ed. by Lola Badia and Albert Soler, Textos i Estudis de Cultura Catalana, 36 (Barcelona: Curial; Publicacions de l'Abadia de Montserrat), pp. 69-94

Pujol, Josep. 1996. “"Psallite sapienter”: la gaia ciència en els sermons de Felip de Malla de I4I3 (estudi i edició)', Cultura Neolatina, 56.I-2: I77-250

Pujol, Josep. 20I5. 'Felip de Malla', in Història de la literatura catalana, ed. by Àlex Broch (Barcelona: Enciclopèdia Catalana; Editorial Barcino; Ajuntament de Barcelona), III: Literatura medieval (III): segle XV, ed. by Lola Badia, 370-90

Resta, Gianvito. 1967. 'La conoscenza di Dante in Sicilia nel Tre e Quattrocento', in Atti del Convegno di studi su Dante e la Magna Curia (Palermo, Catania, Messina, 7-11 novembre 1965), ed. by Antonino Pagliaro et al. (Palermo: Centro di Studi Filologici e Linguistici Siciliani), pp. $4 \mathrm{I} 3^{-2}-4$

Richards, Earl Jeffrey.I981. Dante and the 'Roman de la Rose': An Investigation into the Vernacular Narrative Context of the 'Commedia' (Tübingen: Max Niemeyer) $<$ http://dx.doi. org/IO.I5I5/9783III329024>

Richards, Earl Jeffrey. 1985. 'Christine de Pizan and Dante: a reexamination', Archiv für das Studium der neueren Sprachen und Literaturen, 222: IOO-III 
Rico, Francisco. 1983. 'Petrarca y el "humanismo catalán", Actes del Sisè Col-loqui Internacional de Llengua i Literatura Catalanes (Roma, 28 de setembre - 2 d'octubre de 1982), ed. by Giuseppe Tavani and Jordi Pinell (Barcelona: Publicacions de l'Abadia de Montserrat), pp. 257-9I

Riera i Sans, Jaume. 2008. 'Una cançó de despit contra el rei Martí', Mot So Razo, 7: 34-4I

Riquer, Martí de (ed.). I951. Andreu Febrer Poesies, Els Nostres Clàssics A, 68 (Barcelona: Barcino)

Riquer, Martí de (ed.). 1954. Gilabert de Próixita Poesies, Els Nostres Clàssics A, 76 (Barcelona: Barcino)

Riquer, Martí de. 1954-56. 'Guerau i Pere de Queralt', Boletín de la Real Academia de Buenas Letras de Barcelona, 26: I52-55

Riquer, Martí de (ed.). 1959. Obras de Bernat Metge (Barcelona: Universidad de Barcelona)

Riquer, Martí de. I967. 'Il poeta Andreu Febrer, castellano di Catania, primo traduttore della Commedia in catalano', in Atti del Convegno di studi su Dante e la Magna Curia (Palermo, Catania, Messina, 7-11 novembre 1965), ed. by Antonino Pagliaro (Palermo: Centro di Studi Filologici e Linguistici Siciliani), pp. 425-35

Riquer, Martí de. I984. Història de la literatura catalana: part antiga, 2nd edn, 4 vols (Barcelona: Ariel) (Ist edn I964)

Roccaro, Cataldo. 1987. 'I Sermones di Ruggero da Piazza', in Musco ed. r987, pp. 273-94

Roccaro, Cataldo (ed.). 1992. Rogerii da Platea O. Min. Sermones, Francescana, I (Palermo: Officina di Studi Medievali), I

Romano, David. I975-76. 'Noves biogràfiques del poeta Andreu Febrer (I375?-I440?)', Boletín de la Real Academia de Buenas Letras de Barcelona, 36: 125-32

Romano, David. I980. 'Terzina della Commedia in una lettera in siciliano (Palermo I413)', Medioevo Romanzo, 7. IOO-IIO

Romano, Marta M. M. 20o8. 'Il Quadragesimale di frate Ruggero: status quaestionis e proposte di lavoro', Schede Medievali, 46: I69-77

Romano, Vincenzo (ed.). I95I. Giovanni Boccaccio Genealogie deorum gentilium libri XV, 2 vols (Bari: Laterza)

Rossi, Luca Carlo (ed.). 1990. Le Chiose ambrosiane alla 'Commedia'(Pisa: Scuola Normale Superiore)

Rossi, Luca Carlo (ed.). r999. Dante Alighieri Vita nova, Classici, 468 (Milano: Mondadori)

Rotolo, Filippo. I96I. 'I francescani e i re aragonesi di Sicilia', Miscellanea Francescana, 6I, 54-9I

Rotolo, Filippo. 1984. 'Fra Ubertino de Piagerio da Corleone, O.Min. († 1399): una figura emblematica del francescanesimo del sec. XIV", Miscellanea Francescana, 84: 7I4-43

Rotolo, Filippo. 2007. 'Alla corte di Federico IV Re di Sicilia (I355-I377)', in Musco ed. 2007, pp. $877-900$

Rouy, François (ed.). I989. Alain Chartier Le Livre de l'Espérance, Bibliothèque du Xve Siècle, $5^{\mathrm{I}}$ (Paris: Honoré Champion)

Rubió i Balaguer, Jordi. 1984-86. Història de la literatura catalana, 3 vols (Barcelona: Departament de Cultura de la Generalitat de Catalunya; Publicacions de l'Abadia de Montserrat) (Ist edn I948- 
59)

Rubió i Lluch, Antoni. 1908-2I. Documents per l'història de la cultura catalana mig-eval, 2 vols (Barcelona: Institut d'Estudis Catalans)

Sanchis Sivera, Josep. 1999. 'Bibliología valenciana medieval', in Estudis d'història cultural, Biblioteca Sanchis Guarner, 45 (València: Institut Interuniversitari de Filologia Valenciana; Publicacions de l'Abadia de Montserrat), pp. 57-I24 (ist edn Anales del Centro de Cultura Valenciana, 5-6 (I930): 33-57, 8I-I32)

Santangelo, Giorgio. 1976. 'Fortuna di Dante in Sicilia', in Enciclopedia Dantesca, 2nd edn (Roma: Istituto della Enciclopedia Italiana), v, 223-26

Santangelo, Giorgio. 1985. Dante e la Sicilia e altre 'letture' e note dantesche (Palermo: Flaccovio)

Sanvisenti, Bernardo. 1902. I primi influssi di Dante, del Petrarca e del Boccaccio sulla letteratura spagnuola (Milano: Hoepli)

Sasso, Luigi (ed.). I995. Giovanni Boccaccio Trattatello in laude di Dante (Milano: Garzanti)

Schiff, M. I9O5. La bibliothèque du marquis de Santillane (Paris: Bibliothèque de l’École des Hautes Études)

Schwartz i Luna, Frederic; Carreras i Candi, Francesc (ed.). I892. Manual de novells ardits vulgarment apellat Dietari del antich consell barceloní (Barcelona: Henrich i Companyía), I: I-IX, anys $1390-1446$

Simone, Franco. 1968. Umanesimo, Rinascimento, Barocco in Francia (Milano: Mursia)

Simone, Franco. 1965. 'L'importance historique et littéraire des premières éditions lyonnaises de Dante, Pétrarque et Boccace', Annales de l'Université de Lyon, 3rd ser. (Lettres), 39: 3I-43

Siviero, Donatella (ed.). 1997. Jordi de Sant Jordi L'amoroso cerchio: poesie dell'ultimo trovatore, Biblioteca Medievale, 6 (Milano: Luni)

Solente, Suzanne (ed.). 1959-66. Christine de Pisan Le livre de la mutacion de Fortune, 4 vols (Paris: Picard)

Soler i Palet, J. I92I. 'L'obra del Dante a Catalunya', Catalana 4.92, I5 April, pp. I45-57

Sottili, Agostino. 1975. 'In margine al Catalogo dei codici petrarcheschi per la Germania Occidentale', in Il Petrarca ad Arquà: atti del Convegno di studi nel VI Centenario (1370-1374), ed. by G. Billanovich, G. Frasso, Studi sul Petrarca, 2 (Padova: n.p.), pp. 293-3I4

Spalanca, Carmelo. 1998. 'La fortuna di Dante nella Sicilia del XIV secolo', in Oltre lo Stretto: studi sulla cultura siciliana dal '3oo al 'goo (Caltanissetta: Sciascia), pp. I5-37

Tanturli, Giulio. 20ıo. 'Come si forma il libro delle canzoni', in Le rime di Dante. Atti del Convegno di Gargano del Garda (25-27 settembre 20o8), ed. by C. Berra and P. Borsa (Milano: Cisalpino), pp. II7-34

Tarnowski, Andrea (ed.). 20oo. Christine de Pizan Le chemin de longue étude (Paris: Librairie Générale Française)

Tonelli, Natascia. 20o6. 'Rileggendo le Rime di Dante secondo l'edizione e il commento di Domenico De Robertis: il libro delle canzoni’, Studi e Problemi di Critica Testuale, 73.2: 9-59

Torri, Alessandro (ed.). I829. L'ottimo commento della Divina Commedia, 3 vols (Pisa: N. Capurro; 
repr. Bologna: Arnaldo Forni, I995)

Torró, Jaume. 2002. 'Bernat Metge a Avinyó', in Literatura i cultura a la Corona d'Aragó, ed. by Lola Badia, Miriam Cabré, and Sadurní Martí, Textos i Estudis de Cultura Catalana, 85 (Barcelona: Publicacions de l'Abadia de Montserrat; Curial), pp. 99-III

Torró, Jaume. 20I4. 'La poesia cortesana', in Història de la literatura catalana, ed. by Àlex Broch (Barcelona: Enciclopèdia Catalana; Editorial Barcino; Ajuntament de Barcelona), II: Literatura medieval (II): segles XIV-XV, ed. by Lola Badia, pp.26I-352

Towner, Mary Louis (ed.). 1932. La Vision-Christine, Studies in Romance Languages and Literatures, 6 (Washington DC: Catholic University of America)

Trovato, Paolo; Tonelli, Elisabetta; Bertelli, Sandro; Fiorentini, Leonardo (ed.). 2OI3. 'La tradizione e il testo del carme Ytalie iam certus honos di Giovanni Boccaccio', Studi sul Boccaccio, 4I: I-III

Vielliard, Jeanne. I93o. 'Nouveaux documents sur la culture catalane au Moyen Âge', Estudis Universitaris Catalans, $15: 2 \mathrm{I}-40$

Vives i Liern, Vicent. 1902. Las Casas de los Estudios de Valencia: informe acerca del sitio en que éstas se hallaban emplazadas (València: Viuda de Emilio Pascual)

Volpi, Mirko; Terzi, Arianna (ed.). 20o9. Iacomo della Lana Commento alla 'Commedia', Edizione Nazionale dei Commenti Danteschi, 3, 4 vols (Roma: Salerno)

Willard, Charity Cannon. 1980. 'Christine de Pizan: the Astrologer’s Daughter', in Mélanges à la mémoire de Franco Simone: France et Italie dans la culture européenne, ed. by J. Beck and Gianni Mombello, Bibliothèque Franco Simone, 4, (Genève: Slatkine), I: Moyen Áge et Renaissance, pp. $95^{-I I I}$

Williman, Daniel. 1980. Bibliothèques ecclésiastiques au temps de la papauté d'Avignon, 2 vols (Paris: CNRS), I: Inventaires de bibliothèques et mentions de livres dans les Archives du Vatican (1287-1420): Répertoires; II: Inventaires de prélats et de clercs non français: édition

Wittlin, Curt J. r962. 'Les Manuscrits dits “del Papa Luna” dans deux inventaires de la bibliothèque de Gaspar Johan Sánchez Muñoz à Teruel’, Estudis Romànics, II: II-2I

Zinelli, Fabio. 20I2. 'Il Roman de Cardenois, Guillaume de Machaut e Oton de Grandson tra Francia del sud e Catalogna', Romania, I30.3-4: 294-354 